\title{
COUPLING CFD WITH A ONE-DIMENSIONAL MODEL TO PREDICT THE PERFORMANCE OF REVERSE ELECTRODIALYSIS STACKS
}

\author{
M. La Cerva, M. Di Liberto, L. Gurreri, A. Tamburini*, A. Cipollina, G. Micale, M. Ciofalo \\ Dipartimento dell'Innovazione Industriale e Digitale (DIID) \\ Università degli Studi di Palermo, Viale delle Scienze, 90128 Palermo, Italy
}

\begin{abstract}
Different computer-based simulation models, able to predict the performance of Reverse ElectroDialysis (RED) systems, are currently used to investigate the potentials of alternative designs, to orient experimental activities and to design/optimize prototypes. The simulation approach described here combines a one-dimensional modelling of a RED stack with a fully threedimensional finite volume modelling of the electrolyte channels, either planar or equipped with different spacers or profiled membranes. An advanced three-dimensional code was used to provide correlations for the friction coefficient (based on 3-D solutions of the continuity and Navier-Stokes equations) and the Sherwood numbers (based on 3-D solutions of a scalar transport equation), as well as to test simple models for the Ohmic resistances (based on 3-D solutions of a Laplace equation for the electrical potential). These results were integrated with empirical correlations for the transport properties of electrolytes and membranes, and were used as the input for the higher scale model. The overall model was validated by comparison with experimental data obtained in laboratory-scale RED stacks under controlled conditions. This combined approach constitutes a fully predictive, potentially very accurate, and still extremely fast-running, tool for the approximate simulation of all the main variables, suitable for performance prediction and optimization studies.
\end{abstract}

Keywords: Reverse Electrodialysis; Saline Gradient Energy; Ion Exchange Membrane; Computational Fluid Dynamics; Mass Transfer.

* Corresponding author; email: alessandro.tamburini@unipa.it 


\section{INTRODUCTION: REVERSE ELECTRODIALYSIS}

\subsection{Cell pairs and stacks}

Reverse ElectroDialysis (RED) is an electrochemical membrane-based process that converts the chemical energy associated with the salinity gradient between two solutions into electrical energy. A number of repeating elements named cell pairs (from some units/dozens at laboratory scale [1-2] to some hundreds for prototypes and industrial units [3]) are piled in order to compose a stack, Figure 1(a). Each cell pair, Figure 1(b), includes an anionic exchange membrane $(A E M)$, a concentrate compartment (CONC), a cationic exchange membrane (CEM), and a dilute compartment $(D I L)$, for a total thickness $H_{C P}$ typically less than $1 \mathrm{~mm}$.

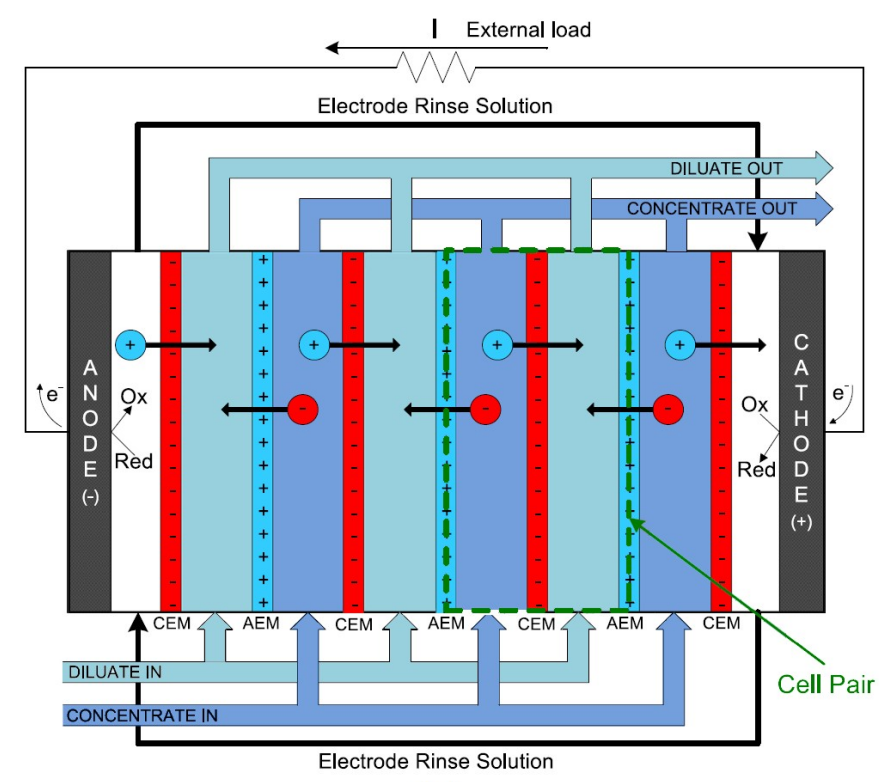

(a)

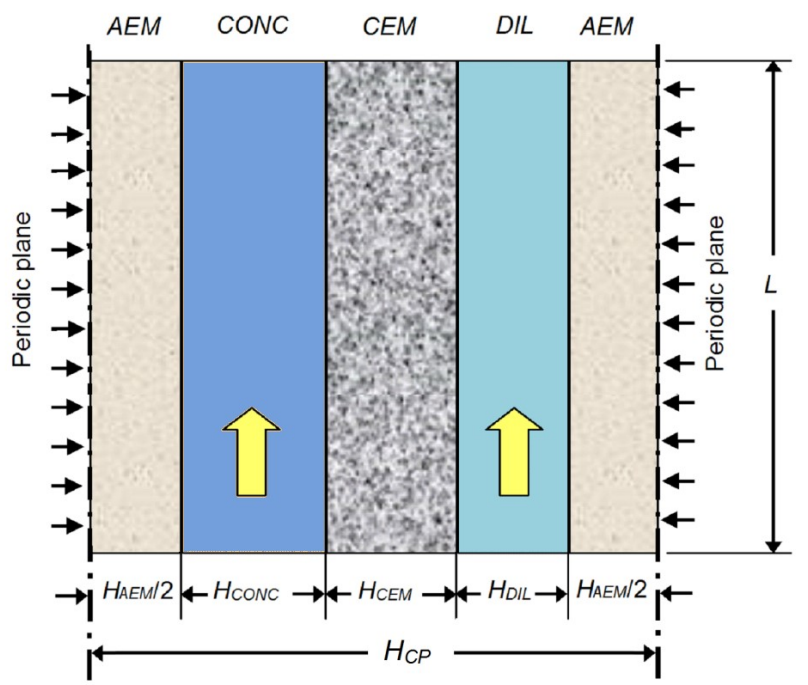

(b)

Figure 1. Schematic representation of a RED stack (a) and of an individual cell pair (b). 
The channels for the fluid flows are created either by spacers or by profiled membranes [4], and their typical thickness is $100 \sim 300 \mu \mathrm{m}$. Typical fluid velocities are of the order of $1 \mathrm{~cm} / \mathrm{s}$. A plate and frame configuration is usually adopted, and parallel-, counter-, and cross-flow arrangements are possible. In principle, counter-flow is preferable since it does not suffer from the axial reduction of the driving force (concentration difference) typical of parallel flow, but it causes larger pressure differences between the concentrate and dilute compartments, which may result in leakage and excessive membrane deformation. The cross-flow arrangement has been shown to perform almost as well as counter-flow [5], and allows more efficient flow distribution strategies which reduce singular pressure losses. The parallel-flow configuration, however, remains the most common, at least at laboratory scale, and thus will be assumed in the present paper.

In the generic channel "SOL" (SOL=either CONC or DIL), of thickness $H^{S O L}$, the corresponding solution enters with a volume flow rate $Q^{S O L}$, an inlet bulk concentration $C_{i}^{S O L}$ and a mean inlet velocity $U_{i}^{S O L}=Q^{S O L} /\left(W \cdot H^{S O L}\right)$, where $W$ is the stack width in the direction orthogonal to the plane of Figure 1 (necessarily shared by the two solutions in the cases of parallelor counter-flow). This definition of mean velocity (superficial velocity) is independent of the presence of spacers or profiled membranes in the channels. The hydraulic diameter of the generic channel will be identified in all cases with $2 H^{S O L}$, i.e., with the hydraulic diameter of a void, laterally indefinite, plane channel. The Reynolds number will be defined as $\mathrm{Re}^{S O L}=U^{S O L} \cdot 2 H^{S O L} / v^{S O L}$. Note that flow rates and mean velocities may vary along the channel, partly because of density variations (caused by concentration variations) and partly because of osmotic trans-membrane water fluxes.

The co-ion exclusion from each ion exchange membrane "IEM" (IEM=either AEM or CEM), or Donnan exclusion, gives rise to an electrical double layer at each $I E M$-solution interface. Here the chemical potential gradient is counterbalanced by an electrical potential gradient (Donnan potential), so that, for open circuit conditions and perfectly permselective membranes, the net ion flux would be nil [6]. An electrical potential difference (membrane potential) is established over each IEM, and the sum of the contributions of all the IEM's in the stack is the open circuit voltage $(\mathrm{OCV})$.

Figure 2 shows qualitative concentration profiles along an arbitrary line crossing a cell pair filled with $\mathrm{NaCl}$ solutions. Double layer phenomena result in sudden jumps of concentration at each IEM-solution interface. Because of the electroneutrality condition, in the solutions the concentrations of $\mathrm{Na}^{+}$and $\mathrm{Cl}^{-}$are the same, while in the membranes they differ by a quantity equal 
to the concentration of fixed charges. Figure 2 shows also concentration polarization phenomena in boundary layers within the fluid domains.

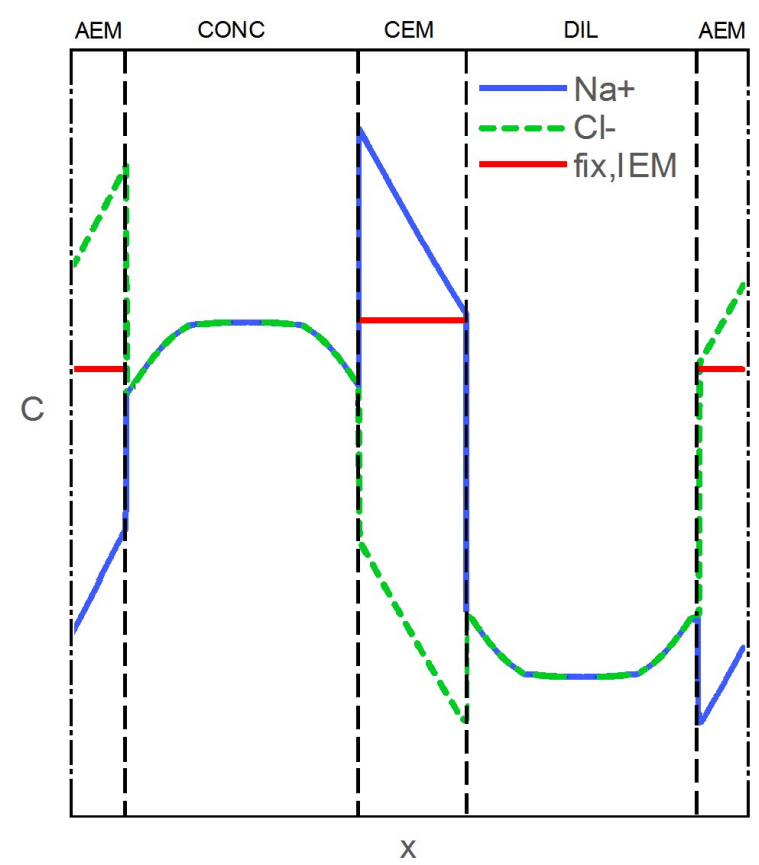

Figure 2. Transversal concentration profiles within a cell pair under closed circuit conditions.

The end compartments are fed by electrode rinse solutions containing an ionic couple [7] and are provided with electrodes which can be connected through an external circuit to an electrical load. When the circuit is closed the voltage at the electrodes causes redox reactions, with release of electrons at the anode and consumption of electrons at the cathode, so that an electrical current flows through the load. As a consequence, cations move through CEM's and anions through $A E M$ 's, from each concentrate channel towards the two neighbouring dilute ones. The voltage over the stack, and thus over the external load, will be given by $O C V$ less the voltage loss due to different phenomena, collectively indicated as the internal resistance of the stack.

\subsection{Net power density}

The net power density which can be provided by a RED stack is determined by the following main aspects: (i) theoretical (maximum) electromotive force, or $O C V$; (ii) Ohmic losses; (iii) non-Ohmic phenomena; and (iv) pumping power consumption [8].

$O C V$ depends mostly on the ratio between the ion activities of the two solutions, but also on the membranes permselectivity. This last parameter is often close to 1 , but, when concentrated solutions are adopted, it can undergo a non-negligible reduction [9]. 
Ohmic losses $\eta_{\Omega}$ are contributed by all the stack elements (membranes, solutions and electrodic compartments). When the dilute channels are fed by a low concentration solution such as riverwater, they give the main contribution to the Ohmic resistance $[10,11]$. When more concentrated solutions are used, the membranes' resistance is the dominant contribution [9]. Spacers may cause a significant increase of the compartment's Ohmic resistance [9-12]; profiled membranes offer a path for the ionic flow through the conducting profiles, so that the electrical resistance may remain unchanged or even decrease, depending on the relative electrical conductivity of membrane and solution. Vermaas et al. [4] reported a reduction of $30 \%$ of the Ohmic resistance in a stack using profiled membranes with respect to a stack provided with spacers; similar findings emerged from a subsequent study [13].

The ion transport across IEMs from the concentrate to the dilute channel causes concentration changes that result in a reduction of driving force and thus in a further voltage drop. This can be split into two contributions: (i) the streamwise concentration change in the bulk of the solution $\left(\eta_{\triangle C}\right)$, and (ii) the transverse concentration change across the diffusion boundary layers $\left(\eta_{B L}\right)$ [7]. The two phenomena are often collectively called "non-Ohmic losses", by analogy with the Ohmic losses. However, the term is misleading because these phenomena do not imply the dissipation of the solutions' chemical potential energy into heat (as "true" losses do), but only its missed conversion into electrical energy (the unconverted energy remains in the solutions). This distinction may be immaterial in "open" RED, performed with naturally occurring solutions, but may be significant in closed-loop systems such as the proposed RED "heat engine" [14].

In regard to $\eta_{\triangle C}$, under ideal conditions it depends only on the ion balance within the channels, but in real stacks it is also affected by the osmotic and electro-osmotic flux of water and by the diffusive flux of co-ions through the membranes $[6,15,16]$. If seawater - riverwater are used, at the flow rates that maximize the net power $\eta_{\Delta C}$ is comparable with the Ohmic resistances $[4,9,13]$.

In regard to $\eta_{B L}$, when an electrical current passes through the stack, a concentration boundary layer develops between each membrane surface and the fluid bulk [6]. The increased salt concentration at the membrane surface in the dilute channel and, conversely, the decreased salt concentration at the membrane surface in the concentrate channel reduce the actual electromotive force [17]. The phenomenon is generally called concentration polarization, although it has been argued that this term should be reserved to ED, while in RED one should speak of concentration depolarization. When the couple seawater - riverwater is used, the contribution of $\eta_{B L}$ to the stack resistance is not negligible $[4,11,17,18]$, though usually lower than axial and Ohmic voltage drops. Convective motions affect mixing and thus the concentration field within the channel; therefore, concentration polarization depends strongly on the channel geometry (size and shape) 
and flow rate [19-21]. A spacer-filled channel may reduce $\eta_{B L}$ with respect to an empty channel [12] and to simple profiled membranes $[4,13]$. Moreover, $\eta_{B L}$ decreases with the inter-membrane distance (channel thickness) $[13,17]$. Both $\eta_{\triangle C}$ and $\eta_{B L}$ may become negligible for highly concentrated solutions $[9,19]$.

Finally, the obtainable net power may be significantly reduced by the energy consumption for pumping the feed solutions. At the flow rate that maximizes the net power this reduction is typically $\sim 10-20 \%[1,4,13,17]$. The total pressure drop through the stack is due to (i) the distribution/collection system (manifolds) and (ii) the channels [20]. A properly designed geometry of the manifolds can drastically reduce their contribution to the hydraulic loss $[13,21]$; on the other hand, the channel features (inter-membrane distance and shape) may have a weighty effect on the net power. Traditional net spacers may lead to pressure drops much higher than in empty channels $[13,19]$, while profiled membranes may enhance only slightly the hydraulic friction $[4,13]$.

Further phenomena may occur in a RED stack, such as parasitic currents [15, 22], fouling [23], and leakages [24]. Their effects depend on the actual constructive details of a stack, are difficult to characterize quantitatively, and thus were not included in the present model.

\subsection{Mathematical modelling of RED}

The mathematical modelling of a complex, multi-physics and multi-scale, process such as RED can be based on different approaches.

On one hand, one may simultaneously take into account all the relevant variables and phenomena and their interaction, including the geometric configuration of the stack, with a minimum of simplifying assumptions. Such a multi-physics approach is made possible, for example, by advanced codes such as $\mathrm{COMSOL}^{\mathrm{TM}}$ [25] and is indeed the most complete. The drawback is that each choice of the independent variables calls for a separate simulation, which may require hours of computing time; moreover, a fully 3-D simulation may require a large amount of memory and become computationally prohibitive. Therefore, this approach remains confined to the accurate simulation of few selected test cases, but is not suitable for parametrical and optimization studies, when a very large amount of different cases (ideally, a continuous configuration space) is to be considered.

An alternative approach, which offers great advantages in terms of computational speed at the price of some loss of accuracy, consists of using a simplified overall model of the stack which, however, incorporates local results (e.g. friction coefficients, mass transfer coefficients or polarization factors, and Ohmic resistances) computed by fully three-dimensional models.

In several previous studies [19, 26-28] we applied Computational Fluid Dynamics to the 
prediction of concentration polarization and frictional pressure losses in channels for Reverse ElectroDialysis, identifying these phenomena as obviously detrimental to the performance of real RED stacks. In particular, refs. [19], [27] and [28] concentrated on the influence of overlapped and woven spacers while ref. [26] considered profiled membranes, bearing pillar protrusions of either square or circular cross section.

However, CFD studies alone can only give qualitative indications on the relative merits and demerits of different configurations (e.g. net spacers versus profiled membranes). A quantitative appreciation of the relative importance of fluid dynamics-dependent quantities in affecting performance parameters (e.g. the maximum obtainable net power density or the minimum solution consumption for a given output) can only come from a proper coupling of CFD with a complete, albeit simplified, model of the RED process.

In this paper, we presented such a coupled strategy, based on combining a one-dimensional model of a RED stack with fully three-dimensional finite volume simulations of the electrolyte channels, including complex configurations (spacers or profiled membranes). An advanced CFD code was used to provide Sherwood numbers and friction coefficients, related, in their turn, to polarization voltage losses and pumping power losses, respectively. Finite-volume 3-D computations were also used to provide areal Ohmic resistances. This last feature is a novelty with respect to the few previous efforts towards the same direction presented in the literature, such as a recent paper by Pawlowski et al. [29], who used the OpenFOAM software package to predict pressure drop and concentration polarization in the presence of membranes with chevron corrugations.

\section{THE ONE-DIMENSIONAL MODEL}

\subsection{General aspects}

In the present model, the variation of bulk concentrations along the flow direction is explicitly simulated by treating them as functions of an axial coordinate $(y)$, while the concentration variation in the direction orthogonal to the membranes is modelled by appropriate polarization coefficients. Note that polarization coefficients $\vartheta$ and boundary layer voltage drops $\eta$, see Eqs. (14)-(20) below, are themselves functions of bulk concentrations and salt flux, and thus vary along the stack.

Figure 3 is a flow chart of the combined approach, which will be presented in details in the following sections. In particular, Section 2 illustrates the one-dimensional model of a cell pair (representative of a whole stack); Section 3 discusses how a number of quantities required by the above models can be extracted from fully three-dimensional CFD simulations; Section 4 presents 
examples of RED stack performance predictions obtained by the above approach; Section 5 discusses the model validation against experimental data.

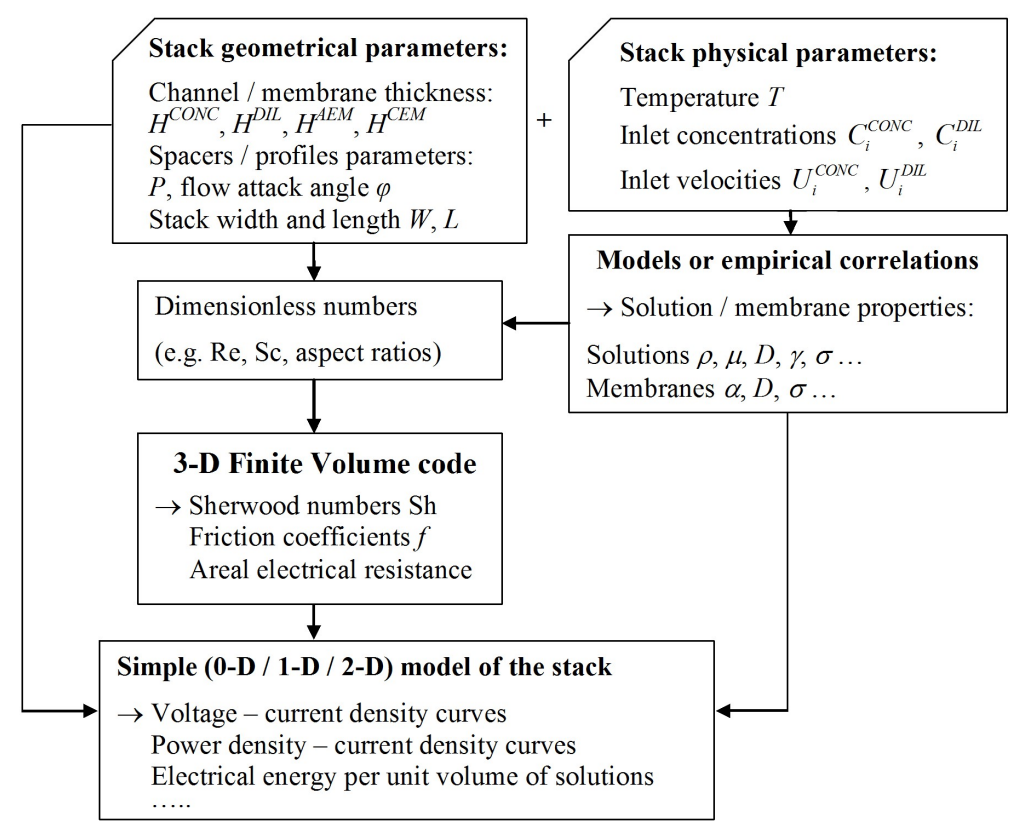

Figure 3. Schematic flow chart of the combined approach to RED performance prediction.

In the following, the number $n_{C P}$ of cell pairs in the stack is left undetermined, and all quantities which are additive with respect to the cell pairs (namely, electrical potential differences) are referred to a single cell pair. Corresponding total quantities can be obtained multiplying by $n_{C P}$. In particular, the areal Ohmic resistance $R_{\text {blank }}$ of the electrode compartments was distributed among all cell pairs as an areal Ohmic resistance $r_{b l a n k}=R_{b l a n k} / n_{C P}$, see also Eq. (13).

In the present model, each ion exchange membrane is characterized by its thickness (and, if appropriate, its shape) and by macroscopic, experimentally accessible, properties (permselectivity, Ohmic areal resistance, salt diffusivity and osmotic permeability). These properties could be derived, in their turn, from more primitive quantities such as the fixed charge density or the matrixwater friction coefficients, taking account of Donnan's equilibria, Maxwell-Stefan's equation and other fundamental laws. Examples can be found in recent papers [30-32], which, on the other hand, adopt a highly simplified treatment of the hydrodynamics and mass transfer in the solution compartments.

\subsection{Modelling assumptions}

As anticipated in Section 1, parallel flow will be assumed in the concentrate and dilute channels. 
The case of counter flow can be dealt with by relatively simple model modifications, while the case of cross flow requires, in principle, a two-dimensional approach. The various electric potential differences in the stack are schematically represented in Figure 4 (profiles are purely qualitative).

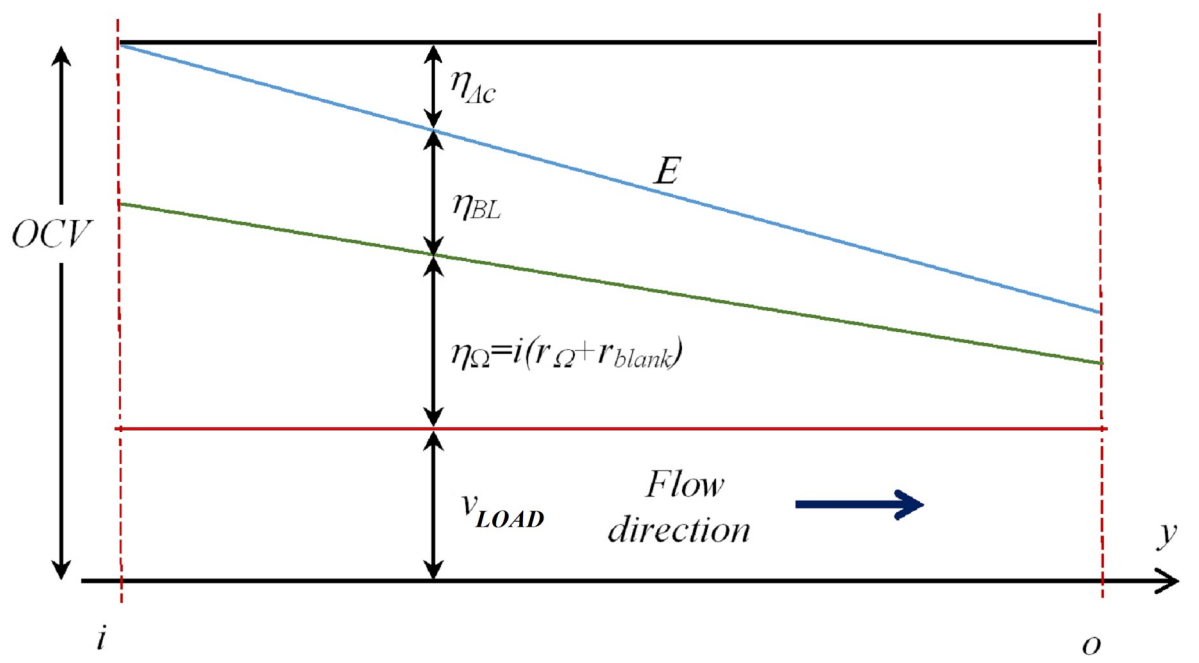

Figure 4. Electric potentials in a cell pair. $i=$ inlet, $o=$ outlet, $y=$ flow direction, $O C V=$ open circuit voltage, $E=$ local electromotive force, $\eta_{\triangle c}=$ voltage drop due to concentration changes along $y, \eta_{B L}=$ voltage drop due to concentration polarization, $\eta_{\Omega}=i\left(r_{\Omega}+r_{\text {blank }}\right)=$ Ohmic voltage loss, $v_{L O A D}=$ electric potential difference across the external load divided by the number of cell pairs.

The generic solution $S O L$ can be characterized either by the two quantities $Q^{S O L}$ (volume flow rate in $\mathrm{m}^{3} / \mathrm{s}$ ) and $C^{S O L}$ (bulk salt concentration in $\mathrm{mol} / \mathrm{m}^{3}$ ), or by the two quantities $G_{W}^{S O L}$ and $G_{S}^{S O L}$ (mass flow rates of water and salt, respectively, expressed in $\mathrm{kg} / \mathrm{s}$ ). The two pairs of quantities, all functions of the streamwise coordinate $y$, are related by:

$$
G_{S}^{S O L}=M_{S} C^{S O L} Q^{S O L} ; \quad G_{W}^{S O L}=\rho^{S O L} Q^{S O L}-G_{S}^{S O L}
$$

and, conversely,

$$
C^{S O L}=\frac{G_{S}^{S O L} \rho^{S O L}}{M_{S}\left(G_{W}^{S O L}+G_{S}^{S O L}\right)} ; \quad Q^{S O L}=\frac{G_{W}^{S O L}+G_{S}^{S O L}}{\rho^{S O L}}
$$

in which $M_{S}$ is the molar mass of salt in $\mathrm{kg} / \mathrm{mol}\left(58.443 \times 10^{-3}\right.$ for $\left.\mathrm{NaCl}\right)$ and $\rho^{S O L}$ is the density of the solution, function of concentration and temperature (see Annex 1). Depending on the balance to be expressed, the use of one or the other couple of quantities may be more convenient.

In particular, mass balances of water and salt along the channels are better expressed in terms of mass flow rates as: 


$$
\begin{aligned}
& \frac{d G_{W}^{C O N C}}{d y}=-\frac{d G_{W}^{D I L}}{d y}=\rho_{W} J_{W} W \\
& \frac{d G_{S}^{C O N C}}{d y}=-\frac{d G_{S}^{D I L}}{d y}=-M_{S} N_{S} W
\end{aligned}
$$

in which $\rho_{W}$ is the density of water at the working temperature $T . J_{W}$ is the overall trans-membrane water flux in $\mathrm{m}^{3} /\left(\mathrm{m}^{2} \mathrm{~s}\right)$, given by the difference of an osmotic and an electro-osmotic term:

$$
J_{W}=J_{W, O S M}-J_{W, E . O S M}
$$

The osmotic term, always directed from the dilute to the concentrate channel, can be expressed as:

$$
J_{W, O S M}=L_{p, A E M}\left(\pi_{A E M}^{C O N C}-\pi_{A E M}^{D I L}\right)+L_{p, C E M}\left(\pi_{C E M}^{C O N C}-\pi_{C E M}^{D I L}\right)
$$

in which $L_{p, I E M}$ is the osmotic permeability of the generic membrane $I E M$, usually measured in $\mathrm{ml} /\left(\mathrm{m}^{2} \mathrm{~h}\right.$ bar) (but SI units are $\left.\mathrm{m}^{3} /\left(\mathrm{m}^{2} \mathrm{~s} \mathrm{~Pa}\right)\right)$; and $\pi_{I E M}^{S O L}$ is the osmotic pressure corresponding to the interface concentration $C_{I E M}^{S O L}$ at the interface between the $S O L$ channel and the IEM membrane (so that there are four of these terms). Osmotic pressures can be accurately computed as functions of the concentrations by Pitzer's correlations $[33,34]$. For $\mathrm{NaCl}$ solutions, tese can be replaced to a good approximation by the simple correlations reported in Annex 1.

The electro-osmotic term can be computed as

$$
J_{W, E . O S M}=n_{H} N_{S} \frac{M_{W}}{\rho_{W}}
$$

where $n_{H}$ is the hydration number, which can be assumed to be 7 for $\mathrm{NaCl}$, and $N_{S}$ is the overall molar salt flux between concentrate and dilute channels (which will be better discussed below). Strictly, one should speak of distinct ionic hydration numbers (e.g. 6 for $\mathrm{Na}^{+}$and 8 for $\mathrm{Cl}^{-}[35]$ ); however, a single "salt hydration number" $n_{H}$ is an acceptable approximation for what is itself a small contribution to the overall species balance in the stack. Note that in RED the salt flux is always from the concentrate to the dilute solution, so that the electro-osmotic water flux is always opposite to the osmotic one.

The molar salt flux $N_{S}$ consists of two components: a Coulombic one, proportional to the local current density $i$, and a diffusive one which would be zero for perfectly perm-selective membranes:

$$
N_{S}=N_{S}^{C O U L}+N_{S}^{D I F}
$$

For monovalent ions, the Coulombic salt flux can be written as: 


$$
N_{S}^{\text {COUL }}=\frac{i}{F}
$$

while the diffusive salt flux entering the overall balance (8) can be written as

$$
N_{S}^{D I F}=N_{S, A E M}^{D I F}+N_{S, C E M}^{D I F}=\frac{D_{A E M}}{H_{A E M}}\left(C_{A E M}^{C O N C}-C_{A E M}^{D I L}\right)+\frac{D_{C E M}}{H_{C E M}}\left(C_{C E M}^{C O N C}-C_{C E M}^{D I L}\right)
$$

in which $D_{I E M}$ is the salt diffusivity in the generic membrane, usually ranging from $10^{-12}$ to $10^{-10}$ $\mathrm{m}^{2} / \mathrm{s}$ and thus much smaller than the diffusivity in solution $\left(\sim 10^{-9} \mathrm{~m}^{2} / \mathrm{s}\right)$. Strictly, Eq. (10) holds only for planar membranes; for profiled membranes, it should be replaced by more complex formulae, or used with suitable equivalent thicknesses. The Coulombic salt flux $N_{S}^{\text {COUL }}$ remains constant across the cell pair, and - like $i$ - is a function of $y$ only, whereas the diffusive salt flux takes different values across different membranes.

In order to close the above system of balance equations, it is necessary to express the electric current density as a function of the cell pair potentials, and these latter as functions of the concentrations. For monovalent ions, the open circuit voltage $(O C V)$, or electromotive force, associated with each cell pair can be expressed by the Nernst law as [6]

$$
O C V=\left(\alpha_{A E M}+\alpha_{C E M}\right) \frac{R T}{F} \ln \frac{\gamma_{i}^{C O N C} C_{i}^{C O N C}}{\gamma_{i}^{D I L} C_{i}^{D I L}}
$$

in which $\alpha_{A E M}, \alpha_{C E M}$ are the perm-selectivities of the anionic and cationic exchange membranes, $C_{i}^{C O N C}$ and $C_{i}^{D I L}$ are the inlet bulk concentrations of the concentrate and dilute solutions and $\gamma_{i}^{\text {CONC }}$, $\gamma_{i}^{D L L}$ are the corresponding activity coefficients, while $T$ is the absolute temperature and the physical constants $R, F$ have their standard values as specified in the Nomenclature. The activity coefficients $\gamma$ can be estimated as functions of the concentrations by using Pitzer's model [33, 34], which, for $\mathrm{NaCl}$ solutions, can be replaced to an excellent approximation by the simple correlations reported in Annex 1.

If the electric circuit is closed on an external load $R_{\text {ext }}$, an electric current $I$, corresponding to an average areal current density $\langle i\rangle=I /(L W)$, flows through the load so that the potential difference across it is $V_{L O A D}=I \cdot R_{\text {ext }}$. It is convenient to divide this potential difference by the number $n_{C P}$ of cell pairs, thus obtaining the voltage per cell pair $v_{L O A D}=V_{L O A D} / n_{C P}$. The local electromotive force $E$ (per cell pair), which is a function of $y$ (Figure 4), can be computed from the local solution concentrations (varying along the flow direction $y$ ) as:

$$
E=\left(\alpha_{A E M}+\alpha_{C E M}\right) \frac{R T}{F} \ln \frac{\gamma^{C O N C} C^{C O N C}}{\gamma^{D I L} C^{D I L}}
$$


Note that $E=O C V$ for $y=0$ (inlet). As Figure 4 shows, the local current density $i$ is obtained from

$$
i=\frac{E-\eta_{B L}-v_{L O A D}}{r_{\Omega}+r_{\text {blank }}}
$$

in which $\eta_{B L}$ is the overall (non-Ohmic) voltage drop in a cell pair due to the presence of concentration boundary layers on the four solution-membrane interfaces, $r_{\Omega}$ is the areal Ohmic resistance of channels and membranes in one cell pair, and $r_{\text {blank }}$ is the areal Ohmic resistance of the electrodic compartments divided by the number $n_{C P}$ of cell pairs.

\subsection{Non-Ohmic voltage drop}

In regard to the non-Ohmic voltage drop $\eta_{B L}$, it can be expressed as the sum of four terms:

$$
\eta_{B L}=\eta_{A E M}^{C O N C}+\eta_{C E M}^{C O N C}+\eta_{A E M}^{D I L}+\eta_{C E M}^{D I L}
$$

corresponding to the four solution-membrane interfaces existing in the cell pair. The generic term $\eta_{I E M}^{S O L}$ can be expressed as [6]:

$$
\eta_{I E M}^{S O L}=-\alpha_{I E M} \frac{R T}{F} \ln \left(\vartheta_{I E M}^{S O L}\right)
$$

in which $\vartheta_{I E M}^{S O L}$ is the polarization coefficient, defined as

$$
\vartheta_{I E M}^{S O L}=\min \left\{C_{I E M}^{S O L} / C^{S O L}, C^{S O L} / C_{I E M}^{S O L}\right\}
$$

i.e. as the ratio of the concentration at the SOL-IEM interface (wall) to the bulk concentration in $S O L$ when $S O L$ represents the concentrate channel and as the inverse ratio when $S O L$ represents the dilute channel, so that one always has $\vartheta_{I E M}^{S O L}<1$. Of course, $\vartheta_{I E M}^{S O L} \rightarrow 1$ and $\eta_{I E M}^{S O L} \rightarrow 0$ for the case of perfect mixing.

Each $\vartheta$ term is related to the corresponding Sherwood number, defined as

$$
\operatorname{Sh}_{I E M}^{S O L}= \pm \frac{N_{S, I E M}}{C^{S O L}-C_{I E M}^{S O L}} \cdot \frac{d_{e q}^{S O L}}{D^{S O L}}
$$

in which $N_{S, I E M}$ is the salt flux through the generic membrane IEM, necessarily identical on the two opposite CONC and DIL faces of each membrane and given by

$$
N_{S, I E M}=\frac{N_{S}^{C O U L}}{2}+N_{S, I E M}^{D I F}=\frac{i}{2 F}+\frac{D_{I E M}}{H_{I E M}}\left(C_{I E M}^{C O N C}-C_{I E M}^{D I L}\right)
$$

(see Eqs. (8)-(10)). Also, $d_{e q}^{S O L}$ is the hydraulic diameter of the channel occupied by the solution 
SOL (conventionally identified here with twice the channel height $H^{S O L}$ ), $D^{S O L}$ is the salt diffusivity in solution $S O L$ and the sign is chosen so as to always have $\mathrm{Sh}>0$. From the above definitions, it can easily be shown that

$$
\begin{aligned}
& \vartheta_{I E M}^{C O N C}=1-\frac{N_{S, I E M} \cdot 2 H^{C O N C}}{\operatorname{Sh}_{I E M}^{C O N C} D^{C O N C} C^{C O N C}} \\
& \vartheta_{I E M}^{D I L}=\left[1+\frac{N_{S, I E M} \cdot 2 H^{D I L}}{\operatorname{Sh}_{I E M}^{D L} D^{D I L} C^{D I L}}\right]^{-1}
\end{aligned}
$$

The advantage of using the Sherwood number instead of the polarization coefficient $\vartheta$ is that, unlike $\vartheta$, it depends only on the geometric configuration, on the Reynolds number and (weakly) on the Schmidt number, but not on the specific values of the concentrations and of the current density. For parallel flow in plane channels under boundary conditions intermediate between uniform wall concentration and uniform wall mass flux (as they occur in the present problem), Sh is $\sim 8$ on all four interfaces. For more complex geometries (e.g. spacer-filled channels or profiled membranes), Sh can be computed by the Finite Volume CFD code (see flow chart in Figure 3), using the wellestablished "unit cell" approach [19] as will be discussed in Section 4. Provided the Sh, $U$ and $N$ terms are defined with reference to a nominal channel thickness $H$ and projected surface area $S=L \cdot W$, all the above treatment continues to hold also in these more complex configurations.

\subsection{Ohmic losses}

Only the ideal case of void (spacerless) plane channels interleaved with planar membranes will be discussed in this Section. The more realistic cases of spacer-filled channels (still interleaved with planar membranes) and of profiled membranes will be discussed in the following Sections 4.2 and 4.3 , respectively.

For spacerless plane channels and planar membranes, the areal resistance $r \Omega$ of a cell pair can be computed (see Figure 1) as the series of four resistances:

$$
r_{\Omega}=r^{C O N C}+r^{D I L}+r^{A E M}+r^{C E M}
$$

The areal Ohmic resistance $r^{S O L}$ of a void (spacerless) solution-filled channel is simply

$$
r^{S O L}=\frac{H^{S O L}}{\sigma^{S O L}}
$$

The electrical conductivity $\sigma$ of each solution can be assumed to be a function of its bulk concentration $C$ and can be evaluated using the correlations reported in Annex 1.

In regard to the Ohmic resistance of the membranes, recent and accurate measurements by 
Galama et al. [30] show that, at least for the reinforced homogeneous membranes investigated:

- when a ion exchange membrane is immersed in a single electrolytic solution with concentration $C$, its Ohmic resistance varies with $C$, decreasing steeply as $C$ increases up to $\sim 10 \mathrm{~mol} / \mathrm{m}^{3}$ and then tending to a flat value for higher $C$;

- when the membrane is wet by two electrolytic solutions with different concentrations $C^{C O N C}$, $C^{D I L}$, its Ohmic resistance is mainly a function of $C^{D I L}$ and depends only weakly on $C^{C O N C}$.

For example, for AMX (anion exchange) and CMX (cation exchange) membranes (Neosepta ${ }^{\circ}$, Tokuyama Corporation, Japan), with thickness $H_{A E M}=138 \mu \mathrm{m}, H_{C E M}=181 \mu \mathrm{m}$, the experimental results for $r_{I E M}$ reported in [36] could be approximated well by the simple formula:

$$
r_{I E M}=a+b\left(C^{D I L}\right)^{-c}
$$

with $a=2.8 \times 10^{-4}, b=7 \times 10^{-3}, c=1.25$ (AMX) and $a=2.5 \times 10^{-4}, b=7 \times 10^{-3}, c=1.25(\mathrm{CMX})$ when $C^{D I L}$ is expressed in $\mathrm{mol} / \mathrm{m}^{3}$ and $r_{I E M}$ in $\Omega \mathrm{m}^{2}$.

Strictly, correlations of the form of Eq. (23) hold for a given membrane, i.e. not only for a given membrane composition but also for a given membrane thickness and shape (e.g. profiled membranes). The assumption that $r_{I E M}$ can be expressed as $H_{I E M} / \sigma_{I E M}$, as in a homogeneous resistive slab of electric conductivity $\sigma_{I E M}$, is not supported by experimental evidence and is not consistent with some of the membrane models proposed in the literature [36]. Actually, the whole subject of membrane Ohmic resistivity and of its dependence on thickness, shape and solution concentrations has not been satisfactorily elucidated so far and deserves further investigation.

\subsection{Axial profiles}

The set of equations described above was implemented as a simple algorithm in which, for given $C_{i}^{C O N C}, C_{i}^{D I L}, H^{C O N C}, H^{D I L}, U_{i}^{C O N C}, U_{i}^{D I L}, L, r_{b l a n k}, v_{L O A D}$ and membrane properties, Eqs. (3)-(4) are integrated by finite differences starting from the known inlet concentrations. To this purpose, the stack length $L$ is divided into $n$ elements (e.g. 50). An iterative method is necessary because the current density $i$ depends on $\eta_{B L}$, Eq. (13), but in its turn $\eta_{B L}$ depends on the salt fluxes $N_{S, I E M}$, Eqs. (14)-(15) and (19)-(20), and thus on $i$, Eq. (18).

The algorithm was implemented on different platforms including Excel, G-95 Fortran and gPROMS. A series of preliminary tests were conducted to ensure that, using the same data, different implementations yielded identical results. A grid-independence study showed that the results changed negligibly when the number $n$ of axial subdivisions was made to vary from 10 to 160 , the most grid-sensitive quantity being the axial profile of current density. 
An example of the results computed by this 1-D model is given in Figure 4. This is for the conditions specified in Table 1.

Table 1 - Conditions assumed in the reference case

\begin{tabular}{|l|l|l|l|l|}
\hline Property & CONC solution & DIL solution & AEM membrane & CEM membrane \\
\hline Concentration $C\left(\mathrm{~mol} / \mathrm{m}^{3}\right)$ & 500 & 17 & - & - \\
\hline Thickness $H(\mu \mathrm{m})$ & 300 & 300 & 138 & 181 \\
\hline Inlet velocity $U(\mathrm{~cm} / \mathrm{s})$ & 2 & 2 & - & - \\
\hline Osmotic permeability $L_{p}\left(\mathrm{ml} / \mathrm{m}^{2} \mathrm{~h}\right.$ bar $)$ & - & - & $5[37]$ & $5[37]$ \\
\hline Salt diffusivity $D_{S}\left(\mathrm{~m}^{2} / \mathrm{s}\right)$ & See Annex 1 & See Annex 1 & $5.5 \times 10^{-11}[37]$ & $5.5 \times 10^{-11}[37]$ \\
\hline Hydration number $n_{H}(-)$ & - & - & 7 & 7 \\
\hline Permselectivity $\alpha(-)$ & - & - & $0.90[37]$ & $0.95[37]$ \\
\hline Ohmic areal resistance $r\left(\Omega \mathrm{m}^{2}\right)$ & See Annex 1 & See Annex 1 & Eq. (15) [36] & Eq. (15) [36] \\
\hline
\end{tabular}

In addition, the stack length was assumed to be $0.8 \mathrm{~m}$ and the areal blank resistance per cell pair $5 \times 10^{-5} \Omega \mathrm{m}^{2}$. The potential difference across the external load per cell pair, $v_{L O A D}$, was assumed to be $0.05 \mathrm{~V}$. For the sake of simplicity, both channels were supposed to be void (spacerless).

Figure 5(a) reports axial profiles of bulk concentrations. Note that, for an infinite stack length, these would tend asymptotically to two values $C_{\infty}^{C O N C}, C_{\infty}^{D I L}$ such that the electromotive force $E$, Eq. (12), equals the imposed potential difference $v_{L O A D}$ between the electrodes, so that both the local current density $i$ and the local Ohmic losses $\eta_{\Omega}$ vanish. For realistic stack lengths, this condition is usually far from being reached. 


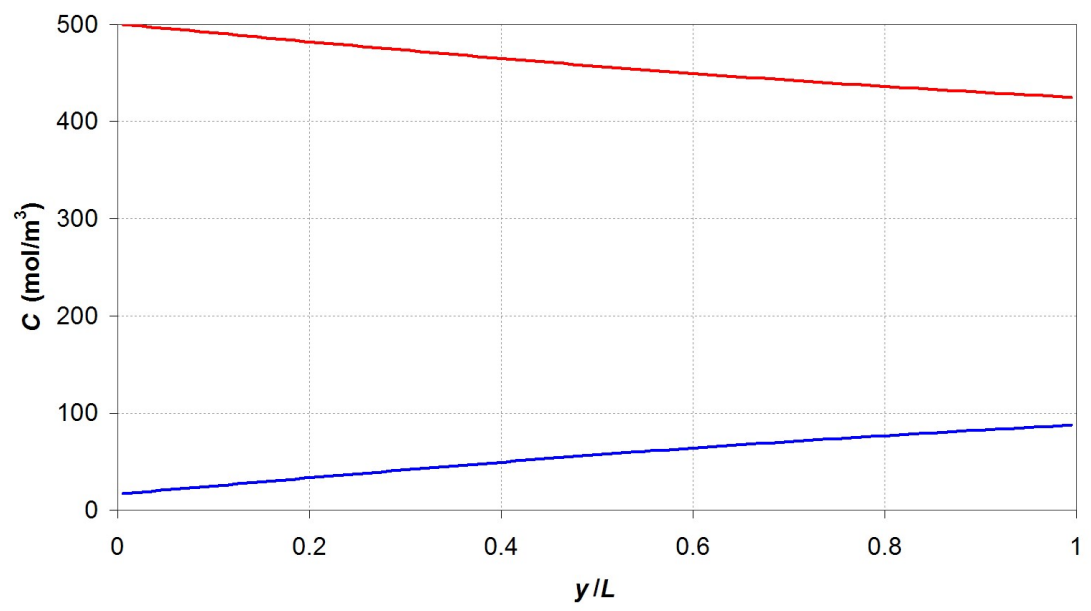

(a)

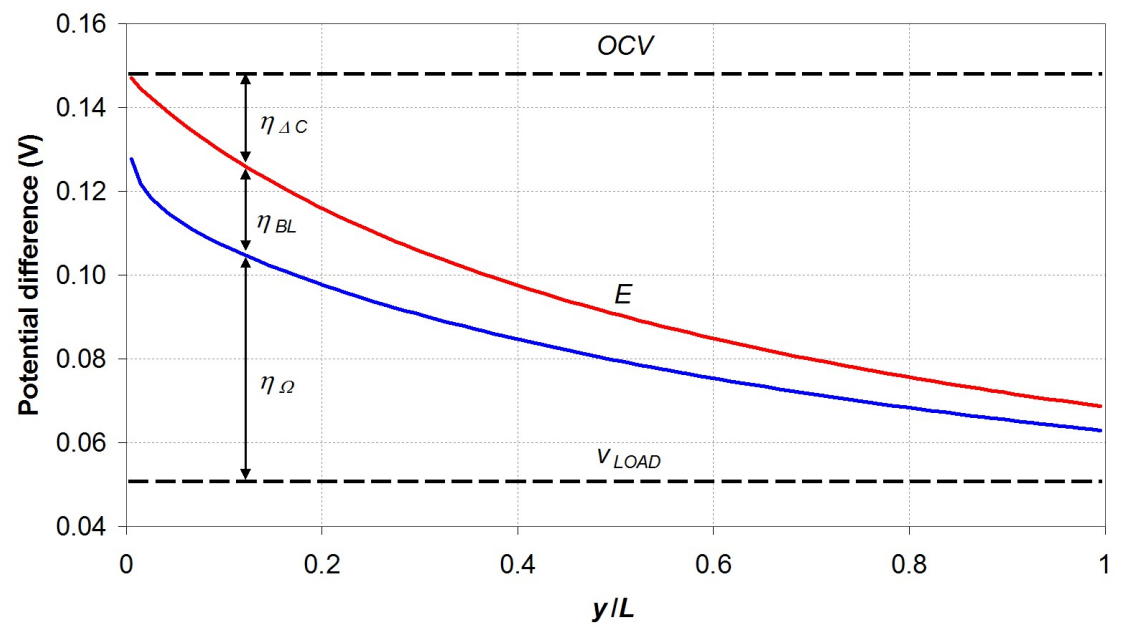

(b)

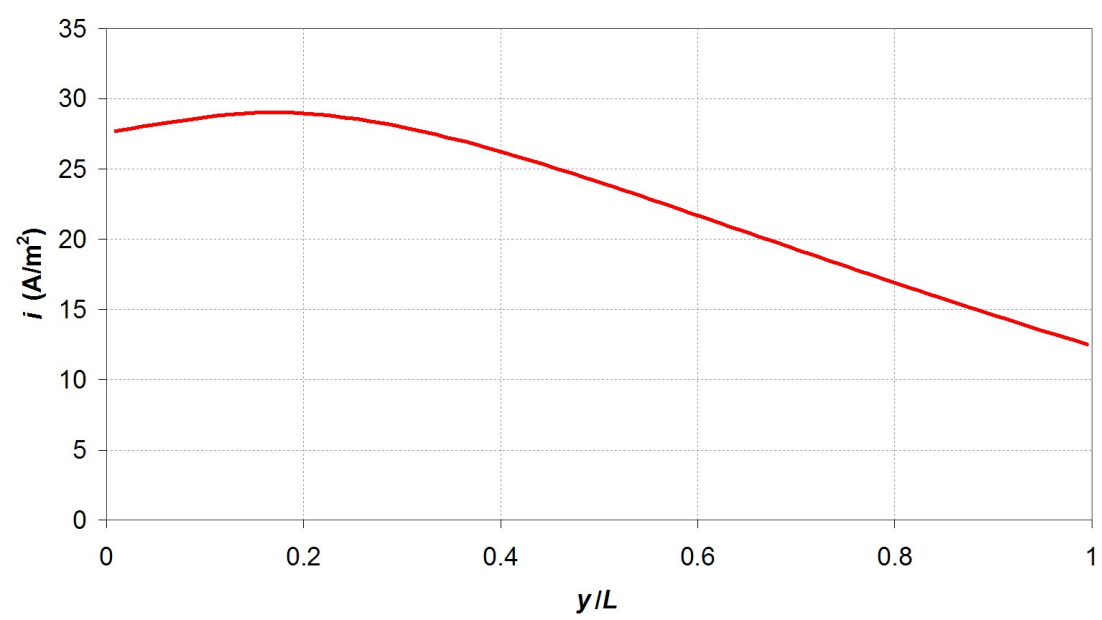

(c)

Figure 5. Axial profiles computed by the 1-D model for the conditions specified in Table 1. (a) concentrations; (b) electric potential differences; (c) current density.

Figure 5(b) reports axial profiles of the same electric potential differences that were schematically shown in Figure 4. Under the conditions considered here, most of the internal potential drop is 
associated with axial concentration variations $\left(\eta_{\Delta C}\right)$ and with Ohmic losses $\left(\eta_{\Omega}\right)$. Note that, as one moves along $y, \eta_{\Delta C}$ increases while $\eta_{\Omega}$ decreases. Non-Ohmic losses associated with concentration changes in the direction orthogonal to the membranes $\left(\eta_{B L}\right)$ are comparable with the other losses only in the first tract of the stack and play a secondary role elsewhere.

Finally, Figure 5(c) reports the axial variation of the electric current density $i$. Note that $i$ initially increases due to the strong reduction of the Ohmic resistivity of the dilute solution. In the second half of the stack, $i$ decreases exponentially with a large relaxation length.

\subsection{Voltage-current characteristic curves}

Figure 5 was obtained by choosing a specific value for the potential difference $v_{L O A D}$ between the electrodes. If $v_{L O A D}$ is made to vary in small steps (e.g. $0.001 \mathrm{~V}$ ) between 0 and $O C V$, currentvoltage characteristic curves like those reported in Figure 6 are obtained.

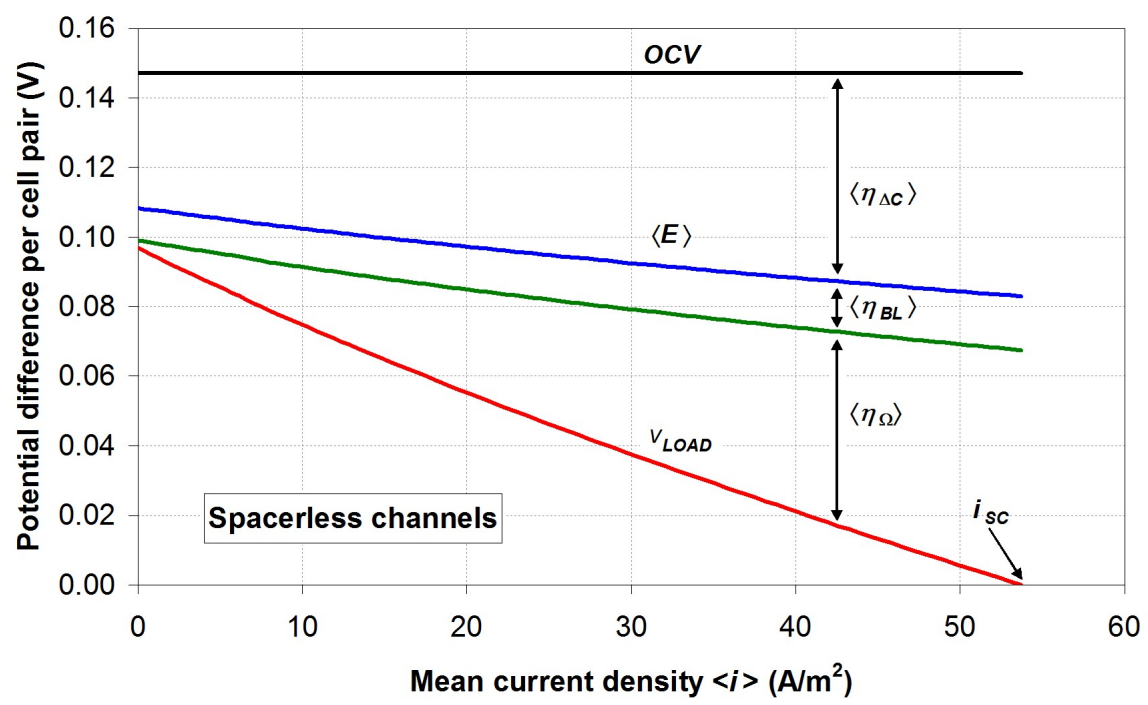

Figure 6. Current density-voltage characteristic curves computed by the 1-D model for the conditions specified in Table 1.

Here, voltage drops and current density $\langle i\rangle$ are mean values, obtained by averaging over the stack length $L$ (or, equivalently, over the stack projected surface $S=L \cdot W$ ). Note that both the open circuit voltage $O C V(\sim 0.147 \mathrm{~V}$ here $)$ and the potential difference $v_{L O A D}$ across the external load $r_{\text {ext }}$ are uniform along the stack and thus do not need averaging. By $i_{S C}$ we denote the short circuit current corresponding to $r_{e x t}=0$ and $v_{L O A D}=0\left(\sim 54 \mathrm{~A} / \mathrm{m}^{2}\right.$ in the present reference case). It can be observed that the axial loss $\eta_{\Delta C}$ would be zero under open circuit conditions $(\langle i\rangle=0)$ in an ideal stack, i.e. in the absence of non-ideal effects (osmotic and electro-osmotic water flux and diffusive salt flux), 
but is significant even at zero current in the real stack considered here. Also polarization losses $\eta_{B L}$ would vanish for $\langle i\rangle=0$ under ideal conditions, but are non-zero here due to the diffusive salt flux. As a consequence, the voltage across the load per cell pair $\left(v_{L O A D}\right)$ under open circuit conditions $\left(r_{e x t} \rightarrow \infty\right)$, which would be equal to $0.147 \mathrm{~V}=O C V$ in an ideal stack, is only $\sim 0.10 \mathrm{~V}$ in the present, real conditions. Only the Ohmic loss $\eta_{\Omega}$ vanishes for $\langle i\rangle=0$ both in an ideal and in a real stack.

The diagram in Figure 6, which is for a single cell pair and per unit area, can be turned into a $V-I$ (total voltage - total current) plot by multiplying $v_{L O A D}$ times $n_{C P}$ (number of cell pairs in the stack) and $\langle i\rangle$ times $S=L \cdot W$ (projected surface area of the stack). As Figure 7 schematically shows, for any given external load $R_{\text {ext }}$ the intersection of the resulting $V(I)$ curve (internal characteristic) with the straight line of slope $R_{\text {ext }}$ (external characteristic) determines the working point $\mathrm{P}$.

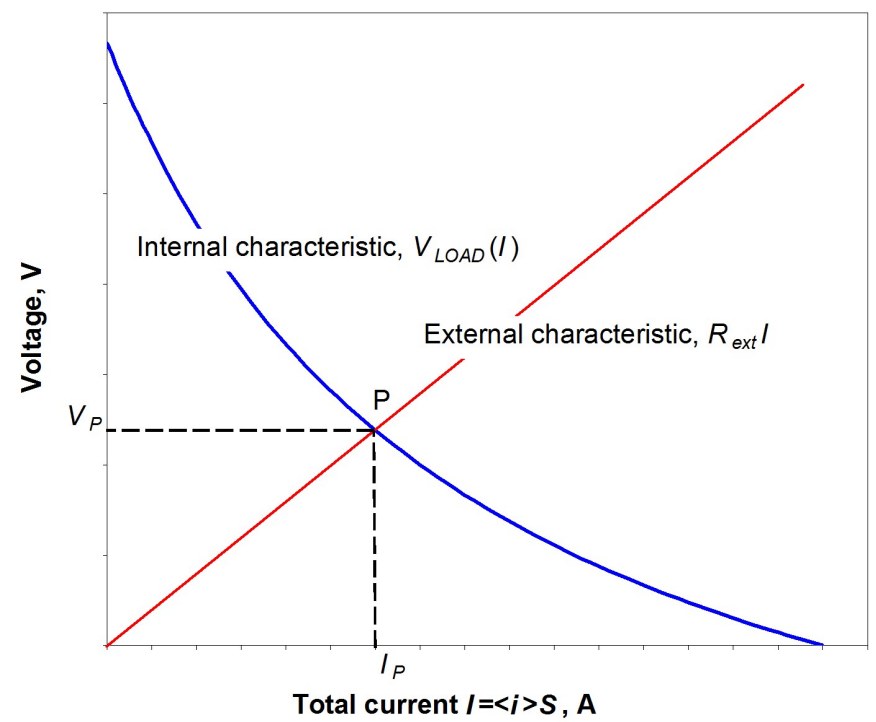

Figure 7. Internal and external characteristics and working point $\mathrm{P}$ (schematic).

For example, for the reference case considered in Figure 6 and a stack with $n_{C P}=100$ and $S=0.64 \mathrm{~m}^{2}$ $\left(L=W=0.8 \mathrm{~m}\right.$ ), the internal characteristic decreases from $\sim n_{\mathrm{CP}} \times 0.1=10 \mathrm{~V}$ for $I=0$ (open circuit) to 0 for $I=54 \times 0.64=34.6$ A (short circuit). For a load resistance $R_{\text {ext }} 10 \mathrm{~V} / 34.6 \mathrm{~A} \approx 0.289 \Omega$ the working point would be at $I_{P} \approx 17.3 \mathrm{~A}, V_{P} \approx 5 \mathrm{~V}$, yielding a gross electrical power of $\sim 86.5 \mathrm{~W}$, close to the maximum that can be extracted from the stack under the given conditions.

\subsection{Pumping power and load curves}

The gross power density GPD (per cell pair) is obtained as 


$$
G P D=v_{L O A D} \times\langle i\rangle
$$

The net power density NPD is obtained by subtracting from GPD the pumping power density $P P D$, associated with pressure losses in the concentrate and diluate channels:

$$
N P D=G P D-P P D
$$

In its turn, $P P D$ can be expressed as:

$$
P P D=\frac{Q^{C O N C} \Delta p^{C O N C}+Q^{D I L} \Delta p^{D I L}}{S \chi}
$$

in which $Q^{S O L}=U^{S O L} H^{S O L} W$ is the volume flow rate in each channel $(S O L=$ either $C O N C$ or $D I L)$, $\Delta p^{S O L}$ is the corresponding pressure loss, $S=L W$ is the (projected) surface area and $\chi$ is the efficiency of the pump.

The distributed pressure drop can be computed as

$$
\Delta p_{\text {dist }}^{S O L}=\int_{0}^{L} f^{S O L} \frac{1}{2 H^{S O L}} \rho^{S O L} \frac{\left(U^{S O L}\right)^{2}}{2} d y
$$

in which $f^{S O L}$ is the Darcy-Weisbach friction coefficient for channels filled with the $S O L$ solution. Note that Eq. (27) allows for the streamwise variation of density and mean velocity of the solution to be taken into account, using the same axial discretization into $n$ elements adopted for the calculation of electrical quantities and concentrations.

For plane channels / membranes in laminar flow, one has $f=96 / \mathrm{Re}$, while, for profiled membranes or spacer-filled channels, $f$ can be computed as a function of Re by CFD simulations of the unit cell for the appropriate geometry (see flow chart in Figure 2 and details in Section 4). Note that the presence of a spacer or of a profiled membrane may enhance the friction coefficients by several times with respect to a void (spacerless) plane channel.

Unlike mass transfer entry effects, at low Re hydrodynamic entry effects extend over only a few hydraulic diameters and thus are negligible due to the very high slenderness ratio of RED channels; for example, even for short and relatively thick ducts, say $L=0.1 \mathrm{~m}$ and $H=400 \mu \mathrm{m}$, one has $L / d_{e q}=125$.

For each channel, singular pressure drops can be collectively modeled as

$$
\Delta p_{\text {sing }}^{S O L}=K^{S O L} \rho^{S O L} \frac{\left(U^{S O L}\right)^{2}}{2}
$$

in which the constant $K^{S O L}$ (singular loss coefficient) accounts for area or direction changes both in the channels proper and in the relevant manifolds. Singular pressure losses in RED stacks may vary 
broadly according to the design chosen for the flow distribution system; it has been reported in the literature [21] that they may amount to a significant fraction of the overall pressure drop. Since, for $f=50-500$ and $L / d_{e q}=10^{2}-10^{3}$ (ranges of values typical of spacer-filled RED channels), the term $f L / d_{e q}$ may vary between $5 \cdot 10^{3}$ and $5 \cdot 10^{5}$, values of $K$ of $10^{3}-10^{5}$ (or even larger) can be expected.

For the same reference case considered in the previous Figures 5 and 6, Figure 8 reports the various computed power density terms (per cell pair) corresponding to the voltage terms in Figure 6 as functions of the average current density $\langle i\rangle$, together with the net power density (per cell pair) $N P D=G P D-P P D$ computed by Eqs. (26)-(28) for $K^{C O N C}=K^{D I L}=10^{4}$ and $\chi=0.7$.

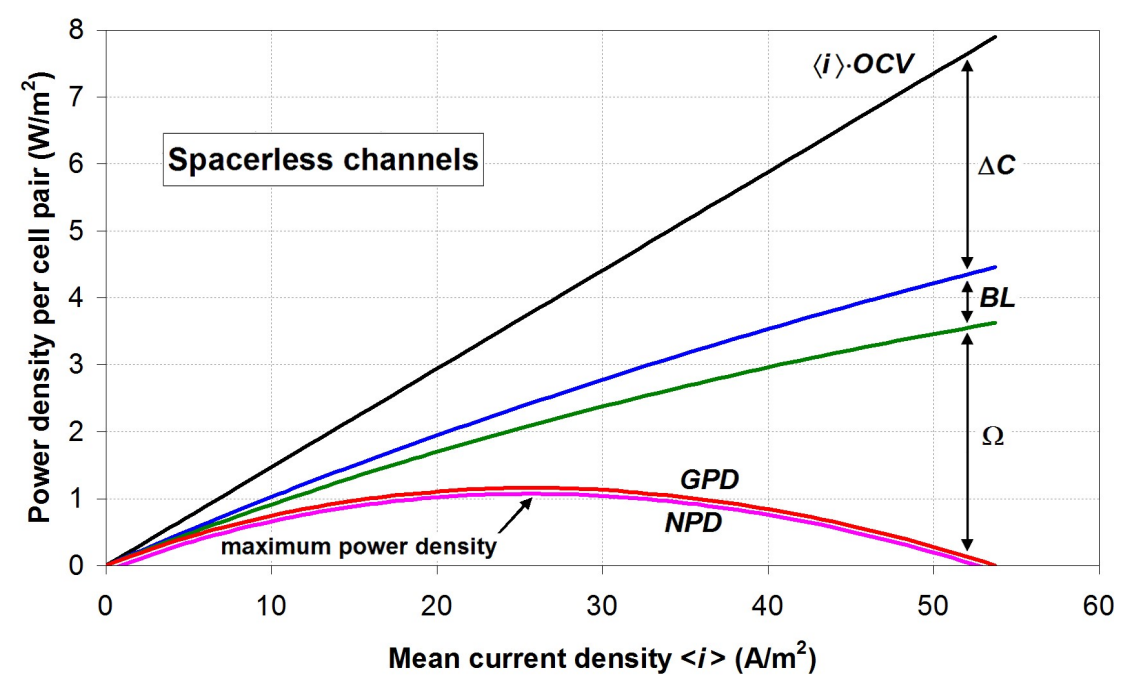

Figure 8. Current density-power density curves computed by the 1-D model for the same configuration as in Figure 5 and $K^{C O N C}=K^{D I L}=10^{4}, \chi=0.7$.

Note that, due to non-Ohmic effects, the maximum gross power density GPD is attained for a mean current density slightly less than one half the short-circuit value $i_{S C}$. The same value of $\langle i\rangle$ maximizes also the net power density NPD since the pumping power density $P P D$ does not depend on $\langle i\rangle$. Note also that, under the present conditions, pumping losses are just a small fraction of the gross power density despite the high values chosen for the singular loss coefficients.

\section{CFD SIMULATIONS}

\subsection{General aspects}

As discussed in Section 1, 3-D CFD simulations were used in the presence of geometrically complex configurations (spacer-filled channels and profiled membranes) in order to obtain quantities that are required by the higher-scale, simplified 1-D model described above: 
- Sherwood numbers $\mathrm{Sh}_{I E M}^{S O L}$ on all four solution-membrane interfaces;

- friction coefficients $f^{S O L}$ in the two fluid compartments.

In all cases, the equation solved were the continuity and momentum (Navier-Stokes) equations written, for simplicity, for a constant-property fluid:

$$
\begin{aligned}
& \frac{\partial u_{j}}{\partial x_{j}}=0 \\
& \frac{\partial u_{i}}{\partial t}+\frac{\partial u_{i} u_{j}}{\partial x_{j}}=-\frac{1}{\rho} \frac{\partial p}{\partial x_{i}}+\frac{\partial}{\partial x_{j}} v \frac{\partial u_{i}}{\partial x_{j}}+a_{s, i}
\end{aligned}
$$

No-slip conditions were imposed at solid walls. Symmetry conditions were imposed at the lateral boundaries, while a "unit cell" treatment was adopted at the inlet-outlet boundaries: translational periodicity was imposed at these faces, while a constant source vector as (force per unit mass, i.e. acceleration), directed along the main flow direction, was adopted as the driving term balancing frictional losses. Note that, with this treatment, $p$ represents the periodic component of pressure, while its large-scale streamwise gradient is $-\rho a_{s}$. Further details of the unit cell approach have been extensively discussed in previous papers concerning Reverse Electrodialysis [19], Membrane Distillation [38] and other problems [39].

The convective-diffusive transport of salt, treated as a neutral species, was described by a scalar transport equation:

$$
\frac{\partial c}{\partial t}+\frac{\partial u_{j} c}{\partial x_{j}}=\frac{\partial}{\partial x_{j}} D \frac{\partial c}{\partial x_{j}}+S_{C}
$$

By analogy with the momentum equations, $c$ represents the periodic component of salt concentration (expressed in $\mathrm{mol} / \mathrm{m}^{3}$ ), while the compensative term $S_{C}$ is included at the right hand side in order to balance salt inflow or outflow through the walls representing fluid-membrane interfaces (note that it is positive for the concentrate channel and negative for the dilute one).

The bulk concentration $C$ was defined in all cases as

$$
C=\frac{1}{Q} \int_{A} u_{s} c d A
$$

in which $A$ is the cross sectional area and $Q=U A$ is the volumetric flow rate. Due to the compensative sink term $S_{C}, C$ is independent of the specific cross section chosen. The unit cellaveraged mass transfer coefficient $k$ on each wall is best defined [40] as 


$$
k=\frac{\left\{N_{w}\right\}}{\left\{c_{w}\right\}-C}
$$

in which $\left\{c_{w}\right\}$ is the wall concentration and $\left\{N_{w}\right\}$ is the molar flux from the wall into the fluid, both averaged over a specific wall (solution-membrane interface) of the unit cell. Note that $\left\{c_{w}\right\}$ and $\left\{N_{w}\right\}$ are still, in general, functions of the axial location along the channels, $y$.

Finally, $k$ is made dimensionless as a Sherwood number $\mathrm{Sh}=k(2 H) / D$. The choice of using as the length scale $2 H$ (i.e., the hydraulic diameter of an indefinite plane channel of the same height) rather than the "true" hydraulic diameter is based on several years' experience in the numerical simulation of reverse electrodialysis and membrane distillation problems [19, 38].

The above flow and transport equations were solved by a finite-volume method using the Ansys-CFX ${ }^{\mathrm{TM}}$ code [41]. Details on meshing, grid independence and numerical methods have been provided elsewhere [19]. The same code was also used to compute the Ohmic areal electric resistance $r \Omega$ of the cell pair by solving the Laplace equation for the electrical potential, $\nabla^{2} \Phi=0$, on the basis of the concentration-dependent electric conductivities of solutions and membranes. The results were used to check the accuracy of simpler models for the cell pair areal resistance.

The further details of the computational technique differ according to whether spacer-filled channels or profiled membranes have to be simulated.

\subsection{Spacer filled channels}

In the case of spacer-filled channels, delimited by planar ion exchange membranes, the CFD simulations were limited to the concentrate and dilute fluid compartments, considered one at a time. At both walls, simulating the solution-membrane interfaces, a third-type (Robin) boundary condition was imposed for the scalar c (concentration):

$$
-\left.D \frac{\partial c}{\partial n}\right|_{\text {wall }}=\frac{\left\{c_{\text {wall }}\right\}-c_{\text {ext }}}{r_{\text {wall }}}
$$

in which $D$ is the salt diffusivity in the solution, $\left\{c_{\text {wall }}\right\}$ is the local concentration at the wall, $c_{e x t}$ is an arbitrary "external" concentration, whose value is irrelevant to the purpose of computing the Sherwood number, and $r_{\text {wall }}$ is a resistance to mass transfer which was set equal to the diffusive resistance of the channel, $H / D$. This choice provides Sherwood numbers intermediate between those that would be computed under conditions of uniform wall concentration $\left(r_{w a l l} \rightarrow 0\right)$ and uniform wall mass flux $\left(r_{\text {wall }} \rightarrow \infty\right)$; however, the dependence of Sh upon $r_{\text {wall }}$ is small.

By way of example, Figure 9(a) shows the computational domain in the case of woven filaments. The channel configuration is completely specified by the pitch-to-channel height ratio 
$P / H$ and by the flow attack angle $\varphi$, defined as the angle formed by the main flow direction with one (arbitrarily chosen) array of filaments. Figure 9(b) shows two fluid compartments filled with identical woven spacers and sandwiched between ionic exchange membranes, to form a periodically repetitive unit of a whole cell pair. In the direction orthogonal to the membranes, periodic planes cut midway through one of the membranes as in Figure 1. Of course, in principle concentrate and dilute channels might have different heights and contain different spacers.

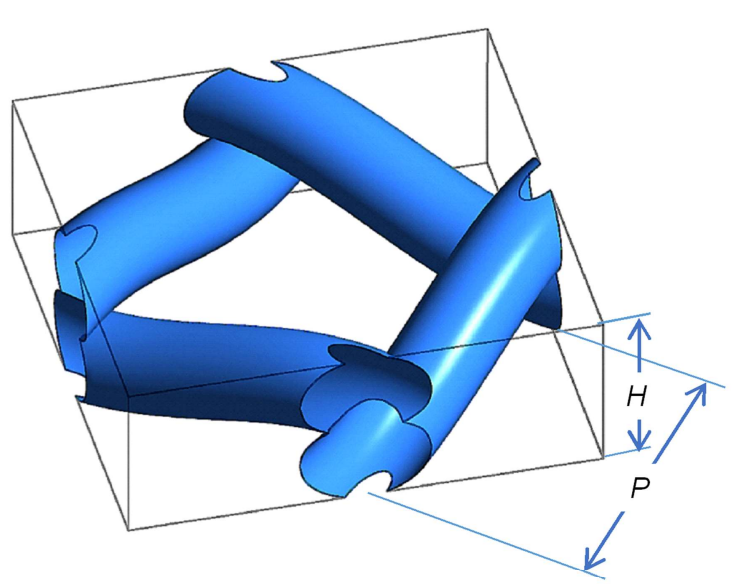

(a)

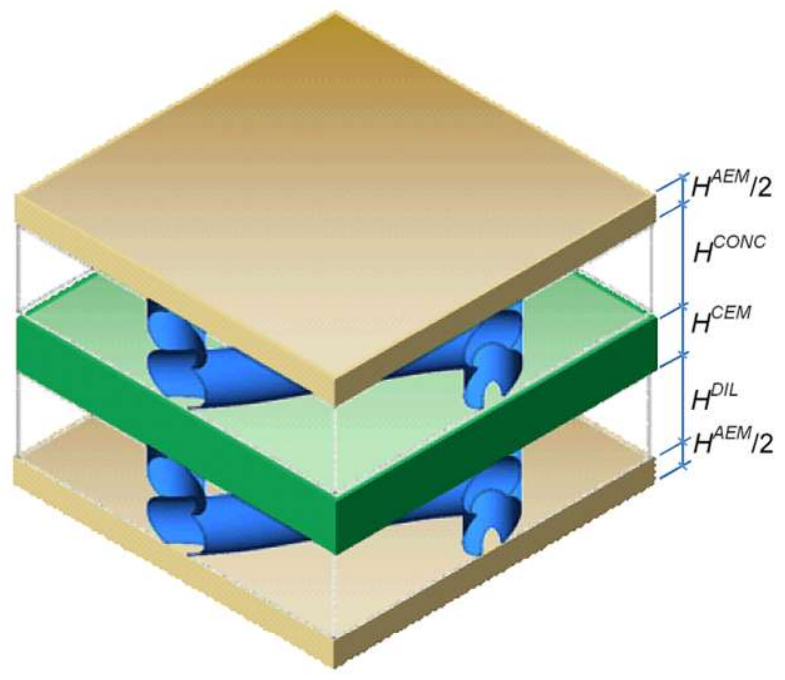

(b)

Figure 9. Channels filled with woven spacers: (a) unit cell (computational domain); (b) concentrate and dilute fluid compartments sandwiched between ionic exchange membranes, to form a periodically repetitive unit of a whole cell pair.

CFD results for the friction coefficient $f$ and the Sherwood number Sh (on each surface) in woven spacers with $P / H=2$ and flow incidence angles $\varphi$ of $0-90^{\circ}$ and $45^{\circ}$ are shown in the range $\operatorname{Re} \leq 70$ (that of the highest interest for RED) in Figure 10. The friction coefficient is normalized by the corresponding factor for parallel flow in an empty (spacerless) plane channel, 96/Re. Best-fit polynomial correlations are also reported; these were used as a basis to evaluate Sh (on each of the four interfaces) and $f$ in the context of the 1-D model described in Section 2.

In Figure 10(a) it can be observed that spacers enhance friction 14 to 20 times with respect to an empty (spacerless) channel. The flow attack angle has a relatively small influence on $f$.

In Figure 10(b) a very large mass transfer enhancement with respect to an empty channel can be observed, together with a stronger influence of the flow attack angle. As Re tends to 0, the Sherwood number Sh tends for both angles to values below the plane-channel Sh, which is $\sim 8$ under third-type boundary conditions; this means that spacers do not promote mass transfer but are actually impairing it because of shadow effects. However, at Reynolds numbers typical of RED 
(e.g. 5-20) a large enhancement is observed, from 4 to 10 times for $\varphi=45^{\circ}$ (flow directed along the diagonal of the spacer diamonds) and from 2 to 5 times for $\varphi=0-90^{\circ}$ (main flow direction orthogonal or parallel to the filaments).

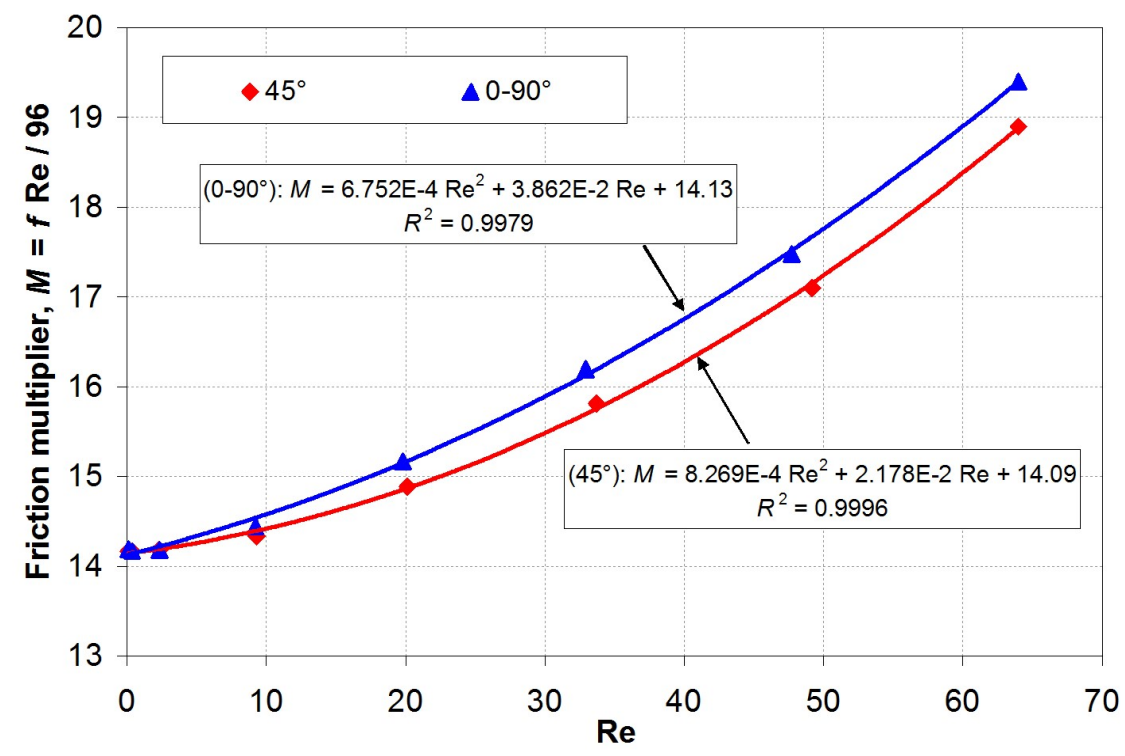

(a)

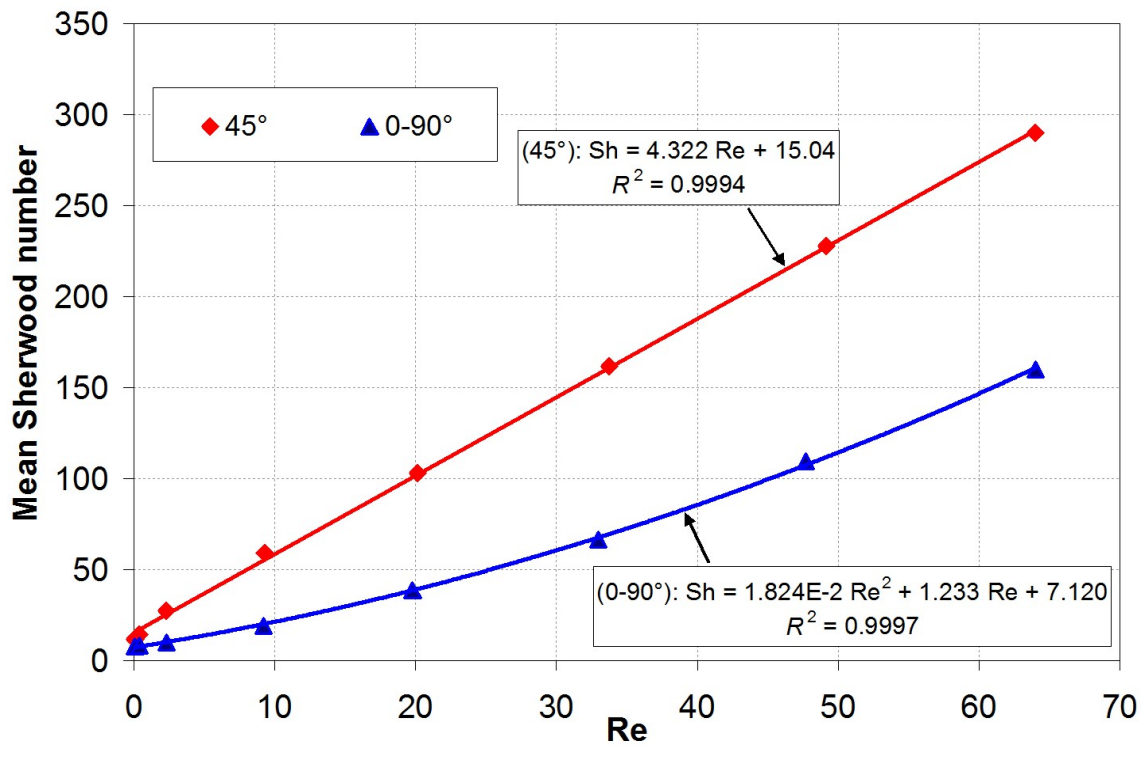

(b)

Figure 10. CFD results (symbols) and best-fit polynomials (lines) for woven spacers with $P / H=2$ and different flow attack angles. (a) friction coefficient multiplier with respect to a spacerless plane channel; (b) mean Sherwood number $(\mathrm{Sc}=600)$.

In regard to Ohmic losses, the areal electrical resistance of a spacer-filled channel can be approximated by:

$$
r^{S O L}=\frac{H^{S O L}}{\varepsilon^{S O L} \sigma^{S O L}}
$$


in which $\varepsilon^{S O L}$ is the porosity, or void ratio $V^{S O L} / V$, which depends only on the spacer geometry. In most cases, simple algebraic expressions can be derived for this quantity; in particular, for woven spacers with $P / H=2, \varepsilon$ is found to be $\sim 0.75$. The areal resistance of the (planar) membranes is assumed to remain the same as in the ideal case of void channels (see Section 2). Solution and membrane resistances are then combined in series to yield the areal resistance $r \Omega$ of a cell pair.

The comparison with accurate 3-D predictions of the areal resistance for some representative configurations, obtained by numerically solving the Laplace equation $\nabla^{2} \Phi=0$ for the electrical potential using the same CFD code adopted for flow and concentration predictions (Ansys-CFX ${ }^{\mathrm{TM}}$ ), has shown that Eq. (35) provides a satisfactory accuracy.

\subsection{Profiled membranes}

In the case of profiled membranes, the separate-channel approach adopted for the numerical simulation of spacer-filled channels is not adequate, because now neither concentration nor electrical potential boundary conditions at the membrane walls are known a priori. Therefore, we chose to perform flow and scalar (salt) transport simulations, and Ohmic resistance calculations, for the cell pair as a whole. In the lateral and streamwise directions, the unit cell approach was retained and periodic boundary conditions were imposed. By way of example, Figure 11 reports the unit cell (computational domain) used for a profiled-membrane configuration that we will call here “Overlapped Crossed Filaments" (OCF).

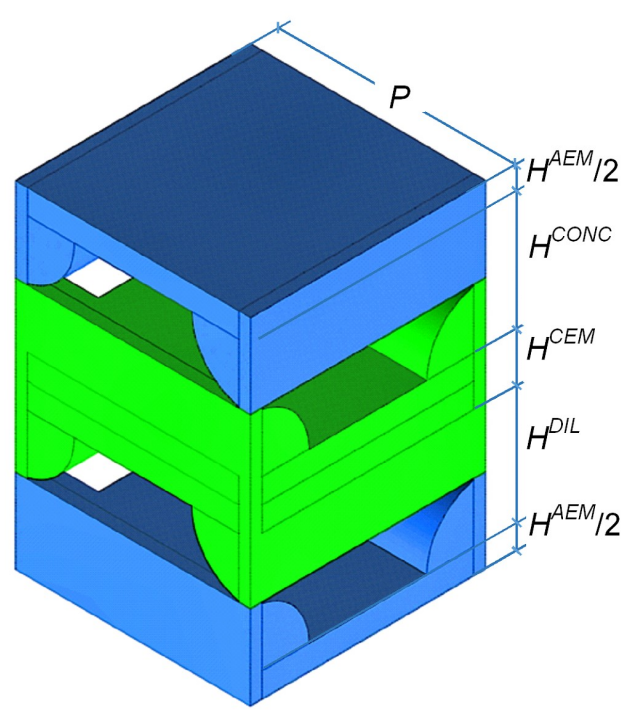

Figure 11. Unit cell (computational domain) used for Overlapped Crossed Filaments (OCF) profiled membranes. 
In this case, a purely diffusive scalar transport equation was solved also in the solid regions (simulating the ion exchange membranes):

$$
\frac{\partial c}{\partial t}=\frac{\partial}{\partial x_{j}} D^{*} \frac{\partial c}{\partial x_{j}}+S_{C}^{*}
$$

in which $D^{*}$ is the diffusivity in the generic membrane and $S_{C}^{*}$ is a suitably defined compensative source term, similar to its counterpart $S_{C}$ adopted in in the fluid compartments, Eq. (31). Two different bulk concentrations were imposed in the two channels, and a single realistic value of the scalar diffusivity $D^{*}$ (typically $10^{-11} \mathrm{~m}^{2} / \mathrm{s}$, much lower than the salt diffusivity in the solutions) was imposed in the membranes to allow a salt flux from the concentrate to the dilute solution. Since the Sherwood numbers depend only marginally on the specific distributions of concentration and molar flux over the walls, the exact choice of $D^{*}$ is immaterial. By this method, at the solid-fluid (membrane-solution) interfaces general interface conditions (continuity of concentration and normal molar flux), and concentration boundary conditions did not need to be assigned.

Results obtained by CFD for the friction coefficient $f$ and the Sherwood number Sh (on each surface) in the range $\operatorname{Re} \leq 70$ are shown in Figure 12 for OCF profiled membranes with $P / H=2$. As in Figure 10, three flow attack angles $\left(0^{\circ}, 45^{\circ}\right.$ and $\left.90^{\circ}\right)$ are considered, best-fit polynomials are reported, and the friction coefficient is normalized by the corresponding coefficient for parallel flow in a plane channel, 96/Re.

In Figure 12(a) it can be observed that, even for low Reynolds numbers, OCF profiled membranes with $P / H=2$ enhance friction with respect to an empty (spacerless) channel by about one order of magnitude (less, however, than corresponding woven spacers in Figure 11). The influence of the flow attack angle on $f$ is small for $\operatorname{Re}<\sim 30$.

In Figure 12(b) it can be observed that, as in the case of woven spacers, for $\operatorname{Re} \rightarrow 0$ mass transfer is not enhanced, and may actually be impaired, by the presence of the membrane profiles $(\mathrm{Sh}<8)$. However, the Sherwood number increases with $\mathrm{Re}$ and, in the range $\mathrm{Re}=5-20$, it becomes considerably larger than in empty channels ( 2 to 4 times for $\varphi=45^{\circ}$, which is again the most effective flow attack angle). The effect, however, is less than in woven spacers (Figure 10).

In regard to Ohmic losses in profiled membranes, in this case neither the membranes nor the channels possess a simple planar shape and thus, strictly speaking, the areal resistance $r \Omega$ of a cell pair cannot be computed by Eq. (21), i.e. as the series of four resistances. Rather, for each channelmembrane configuration, $r_{\Omega}$ should be computed as a whole by solving the Laplace equation for the electrical potential $\Phi$ in three dimensions, provided the membrane can be treated as a homogeneous resistive material of electric conductivity $\sigma$. 


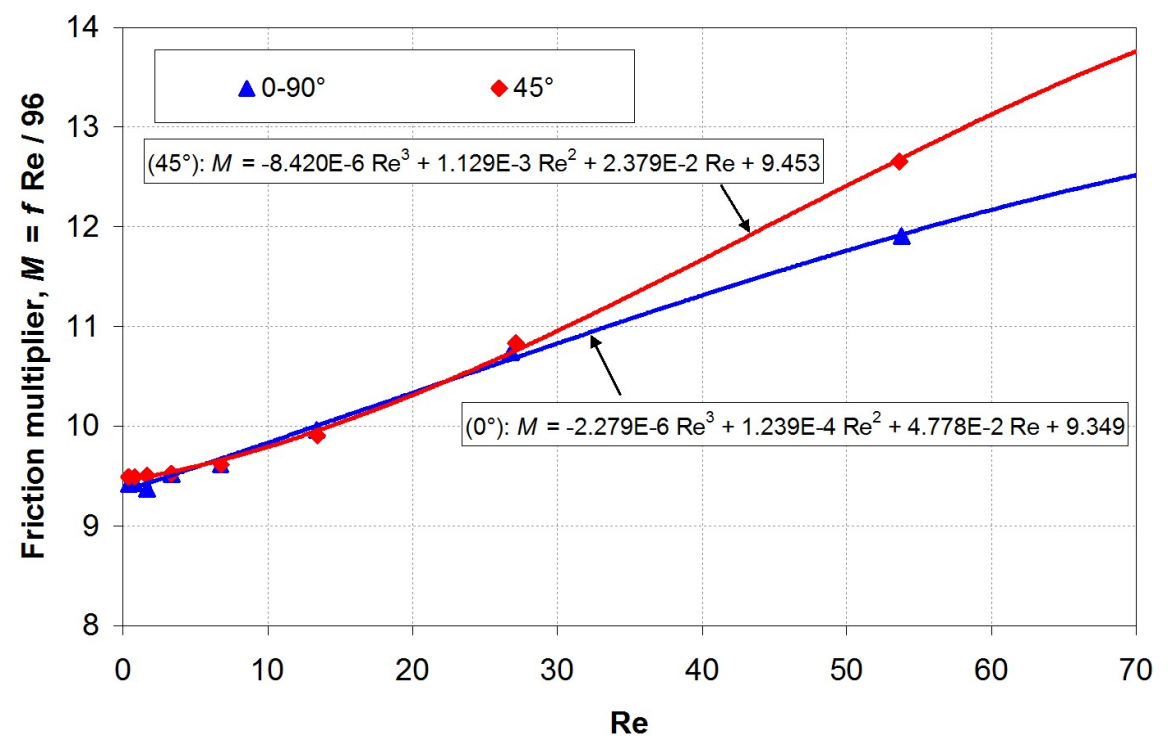

(a)

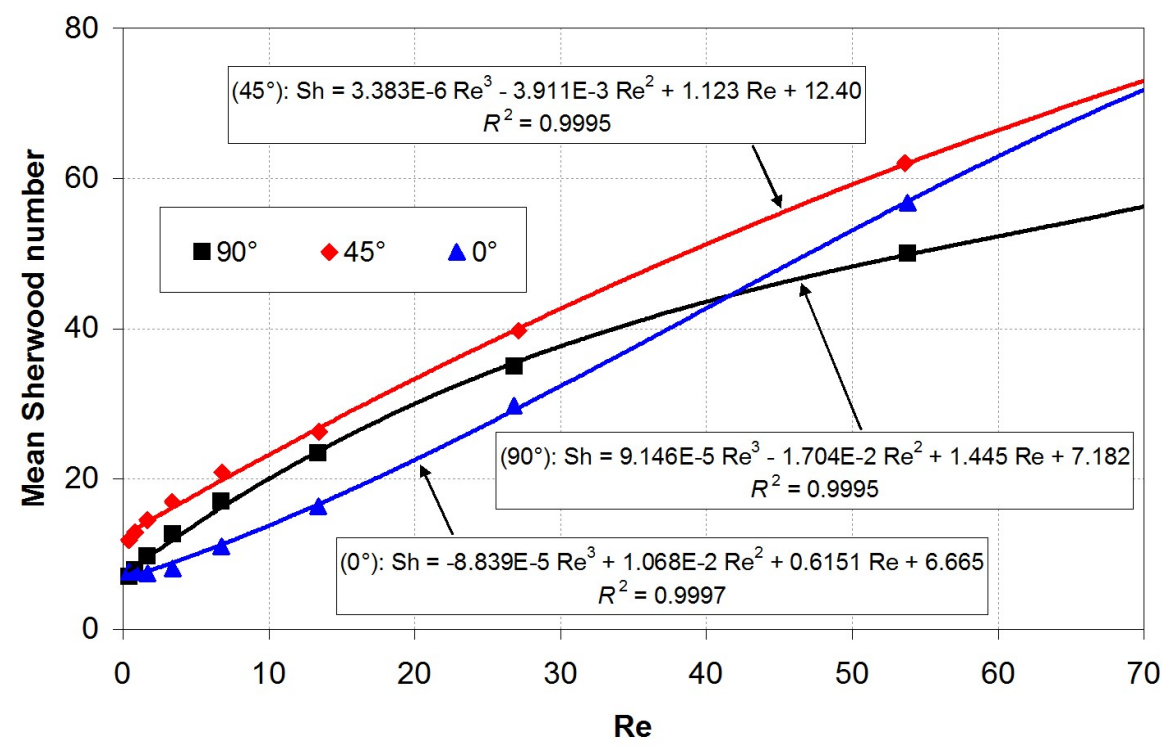

(b)

Figure 12. CFD results (symbols) and best-fit polynomials (lines) for OCF (overlapped crossed filaments) profiled membranes with $P / H=2$ and different flow attack angles. (a) friction coefficient multiplier with respect to a spacerless plane channel; (b) mean Sherwood number $(\mathrm{Sc}=600)$.

However, approximate but simple expressions for $r \Omega$, to be used in conjunction with simplified stack models, are desirable for parametrical design or optimization studies. For OCF membranes like those in Figure 11, a reasonable approximation is to compute the areal resistance of the whole cell pair (see Figure 1) as:

$$
r_{\Omega}=\int_{0}^{H_{C P}} \frac{d x}{\langle\sigma\rangle}
$$


i.e. as the series of the electrical resistances of infinitesimal layers of thickness $\mathrm{d} x$, each characterized by an electrical conductivity $\langle\sigma\rangle=\sum_{k} \sigma_{k}\left(S_{k} / S\right)$, which is the area-weighted average of the electrical conductivities of the various materials present in the generic section.

The integral in Eq. (37) can be reduced to the sum of elementary, though cumbersome, algebraic expressions. Note that even Eq. (35), proposed for spacer-filled channels, can be obtained as a special case of Eq. (37) in the limit of zero electrical conductivity of the filaments.

The accuracy of the above approximation was verified a posteriori by comparing its predictions with accurate, 3-D numerical solutions for the electrical potential, obtained for a few representative cases by the same 3-D code (Ansys-CFX ${ }^{\mathrm{TM}}$ ) used for the assessment of Sh and $f$. Very small discrepancies (a few \% at most) were obtained.

\subsection{Adjustments for concentration effects}

All the Sherwood numbers reported above were computed by CFD for a reference Schmidt number $\mathrm{Sc}_{r e f}=600$, roughly corresponding to solutions of intermediate dilution $\left(C \approx 100 \mathrm{~mol} / \mathrm{m}^{3}\right)$. On the basis of our own sensitivity study, the influence of Sc, and thus of the concentration $C$, can be taken into account by multiplying the reported values of $\mathrm{Sh}$ by $\left(\mathrm{Sc}_{\mathrm{Sc}} \mathrm{Sc}_{r e f}\right)^{1 / 2}$, a factor which becomes significant only for highly concentrated solutions. Only in the case of parallel, fully developed flow in a plane (spacerless) channel the Sherwood number is independent of the Schmidt number and thus does not require any concentration adjustment.

\subsection{Adjustments for entrance effects}

All the values of $f$ and Sh reported above were computed for fully developed flow, either in a plane (spacerless) channel or in the periodic unit of an array of identical cells. In a real, finite-length stack, the local Sherwood number decreases towards its fully developed value $\mathrm{Sh}_{\infty}$ as a function of the dimensionless distance from inlet, $y^{*}=\left(y / d_{h}\right) / \mathrm{Pe}$, where $d_{h}$ is the hydraulic diameter $(=2 H)$ and $\mathrm{Pe}=\mathrm{Re} \cdot \mathrm{Sc}$ is the Peclet number [42]. The inverse of $y^{*}$ is known as the Graetz number $(\mathrm{Gz})$ and the problem of determining Sh in the entry region is known as the Graetz problem. As a rule of thumb, in laminar flow the ratio $\mathrm{Sh} / \mathrm{Sh}_{\infty}$ becomes negligibly different from unity (e.g., <1.05) for $y^{*}>0.02$ while it may be as high as 3-5 for $y^{*}=10^{-4}$. In RED and other mass transfer processes, due to the high value of Sc (e.g. 600) and despite the low values of Re (e.g. 10), Pe may be quite high (e.g. $6000)$, so that the condition $y^{*}=0.02$ is attained for $\left(y / D_{h}\right)=120$. For channels with $H=300 \mu \mathrm{m}$ $\left(d_{h}=600 \mu \mathrm{m}\right)$, this value corresponds to a distance of $0.072 \mathrm{~m}$, so that, in short stacks (e.g. $L=0.1$ $0.2 \mathrm{~m}$ ), entrance effects extend over a large portion of the stack and cannot be neglected. 
Details of the behaviour of Sh in the entrance region depend on the inlet conditions and on the channel's geometry. For laminar flow in circular pipes with simultaneously developing flow and concentration fields, accurate correlations are provided by Gnielinsky [42]. For flat rectangular channels (which include the laterally indefinite plane channel as a limiting case), computational results have been collected by Lee et al. [43]. As an additional test, we have performed accurate numerical simulations for varying Sc and Re in plane channels using Ansys-CFX ${ }^{\mathrm{TM}}$, confirming that the ratio $\mathrm{Sh} / \mathrm{Sh}_{\infty}$ depends only on $y^{*}$ (or $\mathrm{Gz}$ ) and can be approximated by the simple correlation

$$
\frac{\mathrm{Sh}}{\mathrm{Sh}_{\infty}}=C_{G}\left[\mathrm{Gz}+\left(\frac{1}{C_{G}}\right)^{3}\right]^{1 / 3}
$$

with $C_{G} \approx 0.18$. Figure 13 shows Eq. (38) along with results by Lee et al. [43] and our own CFD predictions.

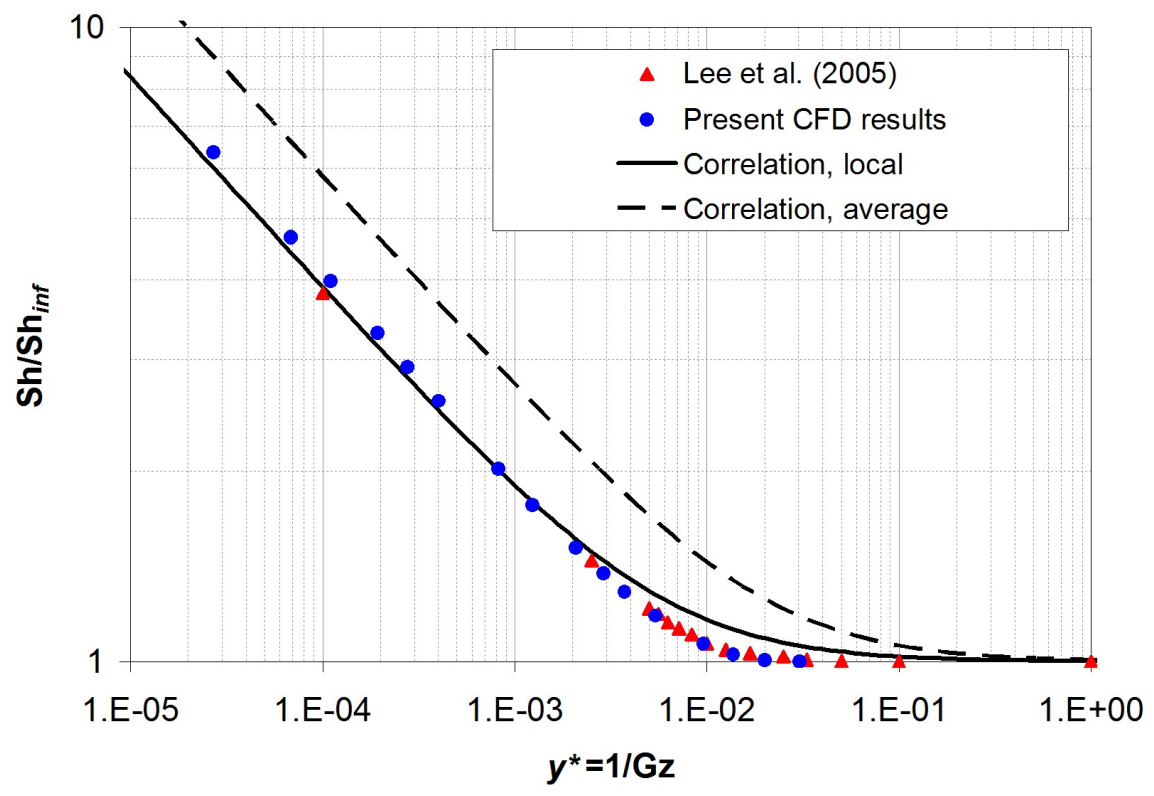

Figure 13. Entrance effects on the Sherwood number in plane channels. Results from the literature and from present CFD calculations are reported along with Eq. (38) (solid line). The broken line represents the correlation for the average Sherwood number in the interval $0-y^{*}$.

Although not very accurate, Eq. (38) was chosen as the simplest correlation exhibiting the correct asymptotic behaviour both for $y^{*} \rightarrow 0$ and for $y^{*} \rightarrow \infty$. It also possesses the nice property that the average of Sh between the channel inlet and the generic axial location can be approximated by a correlation of the same form as the local one, Eq. (38), but with a different constant $C_{G}^{a v g}=(3 / 2) C_{G}(\sim 0.27)$. This is also reported in Figure 13 and shows that, as expected, entrance effects on the average Sh extend far downstream than local effects.

Note that the local multiplier (Eq. (38) with $C_{G}=0.18$ ) should be used in conjunction with the 
1-D stack model described in Section 2, while the average multiplier (Eq. (38) with $C_{G}^{a v g}=0.27$ ) is more suitable for 0-D (lumped parameter) models.

For more realistic channel configurations, involving spacers or profiled membranes, the literature reports few and unclear findings. For example, Shakaib et al. [44] conducted 3-D CFD simulations for developing flow in spacer-filled channels at $\operatorname{Re}>10^{2}, \mathrm{Sc} \approx 650$ and $\varphi=0^{\circ} / 90^{\circ}$; they found that Sh differed significantly from its asymptotic value $\mathrm{Sh}_{\infty}$ only in the first 2 unit cells (see their Figure 3) and exhibited a non-monotonic behaviour on the face adjacent to the filaments at $90^{\circ}$ incidence. On the other hand, Rohlfs and Lienhard [45] conducted numerical simulations for heat transfer in developing flow with transverse cylindrical obstacles floating in a plane channel; they found a $\mathrm{Nu}-y^{*}$ dependence similar to that in Eq. (38) which, for high values of the Prandtl number (equivalent to the Schmidt number for mass transfer), implied that $\mathrm{Nu}$ was significantly higher than its asymptotic value in several unit cells.

While the issue clearly deserves further investigations, in the present work we assumed, for the sake of simplicity, that the same correlation derived for empty channels can be applied to spacerfilled channels or profiled membranes.

\section{COMPARISON OF GEOMETRIES}

As an example of the influence of the channel configuration on the stack performance, Figure 14 reports voltage-current density characteristic curves computed by the combined 1-D / CFD model for the conditions in Table 1 (the same holding for the spacerless channel case in Figures 6-8), but different channel configurations: (a) overlapped (diamond) spacers with $P / H=2$; (b) OCF profiled membranes with $P / H=2$. In both cases, the flow attack angle $\varphi$ was $45^{\circ}$; the comparison with results for other values of $\varphi$ (not reported here for the sake of brevity) shows that the influence of this parameter is only secondary at the present low Reynolds number.

These results should be compared with the corresponding predictions obtained by the same 1D model for the ideal case of a void (spacerless) channel, for which CFD results are not required (Figure 6). The comparative examination of the current density- voltage (per cell pair) curves shows that the relative importance of different voltage losses is about the same in all cases: Ohmic and axial losses are of a similar magnitude, while boundary layer drops play only a secondary role. However, it can be observed that $\eta_{B L}$ is utterly negligible in the case of woven spacers, which cause a very effective mixing, intermediate in the presence of OCF profiled membranes, and largest in the empty channel of Figure 6. Both woven spacers and OCF profiles yield a short-circuit current density slightly larger than the empty channel, showing that, in regard to mass transfer, they perform better than this latter. 


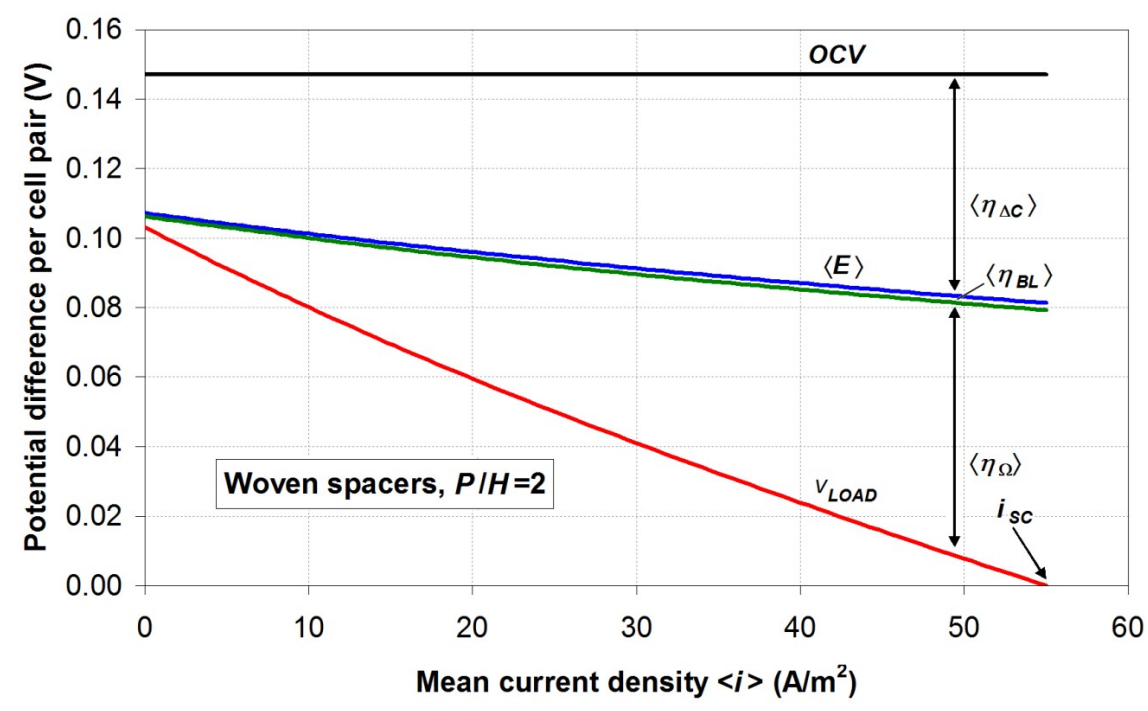

(a)

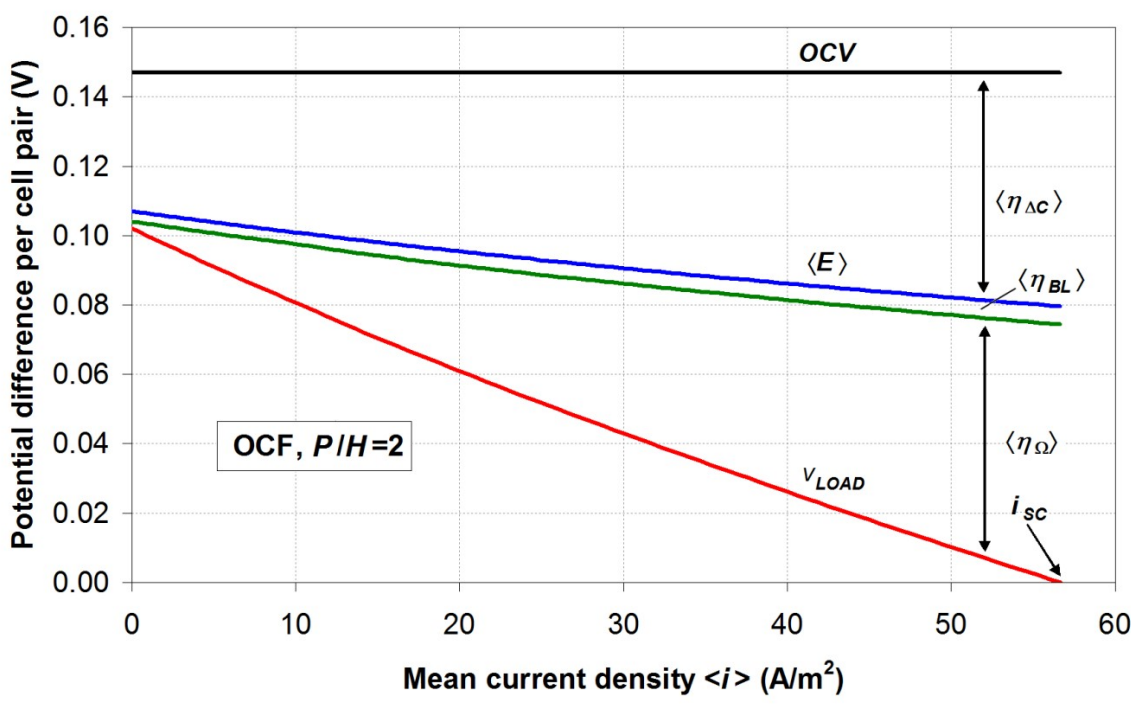

(b)

Figure 14. Current density-voltage curves computed by the 1-D/CFD model for the conditions specified in Table 1 and different configurations: (a) woven spacers with $P / H=2$; (b) OCF profiled membranes with $P / H=2$. The flow attack angle $\varphi$ was $45^{\circ}$ in both cases.

Figure 15 reports power density-current density curves (load curves) for the same configurations as in Figure 14. These highlight the importance of frictional pressure drop: both woven spacers and OCF membranes cause much larger pumping losses than the empty channel, which significantly reduce the net power density. 


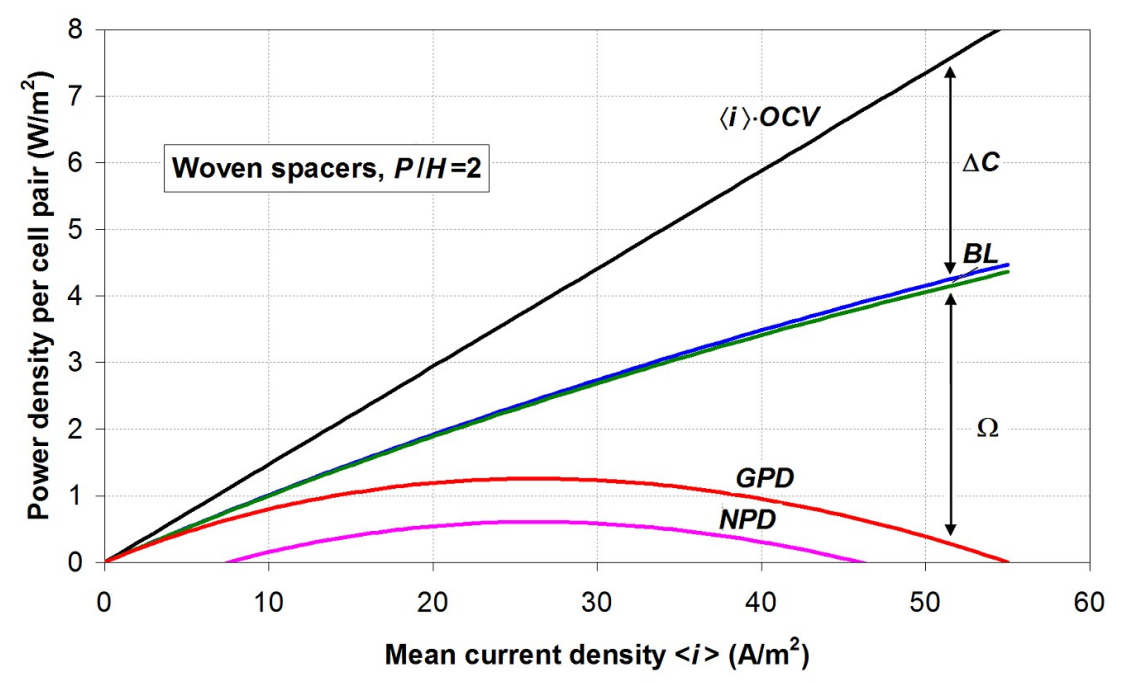

(a)

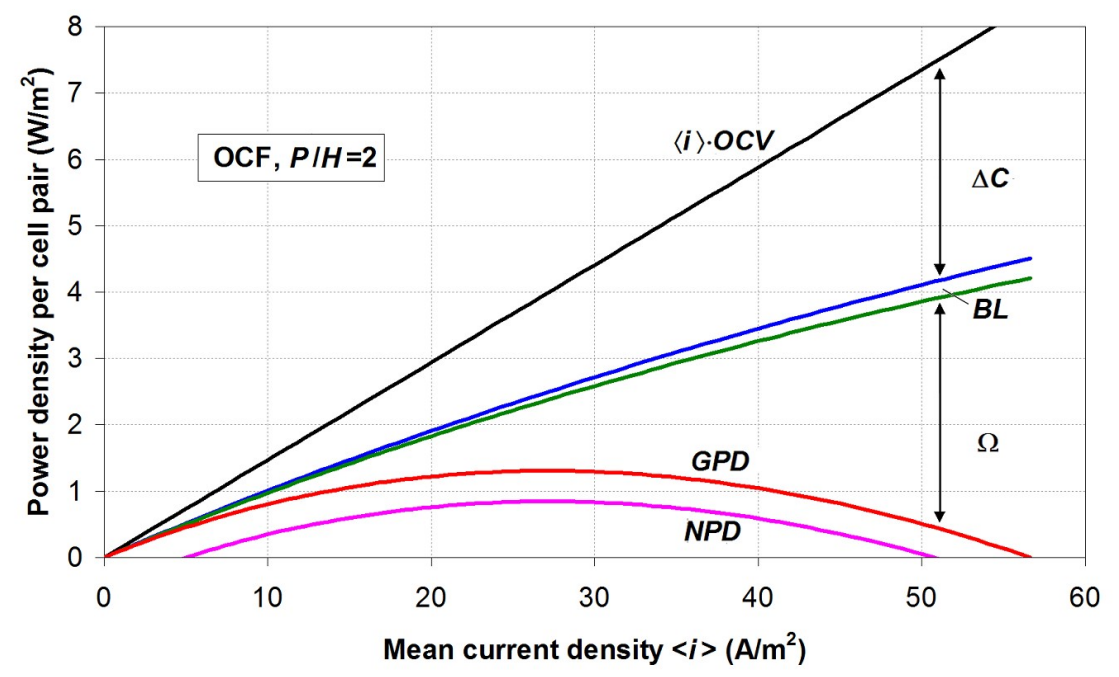

(b)

Figure 15. Current density-power density curves computed by the 1-D/CFD model for the conditions specified in Table 1 and different configurations: (a) woven spacers with $P / H=2$; (b) OCF profiled membranes with $P / H=2$. The flow attack angle $\varphi$ was $45^{\circ}$ in both cases.

An overall comparison between the three geometries examined is given in Figure 16. It reports the gross (a) and net (b) power density (per cell pair), GPD and NPD, as a function of the mean current density $\langle i\rangle$. Figure 16(a) shows that the highest gross power density and the highest short circuit current density are provided by OCF profiles, followed by woven spacers and then by the empty channel. On the other hand, as shown by Figure 16(b), the highest net power density per cell pair is provided by empty channels, followed by OCF profiled membranes and then by woven spacers. 


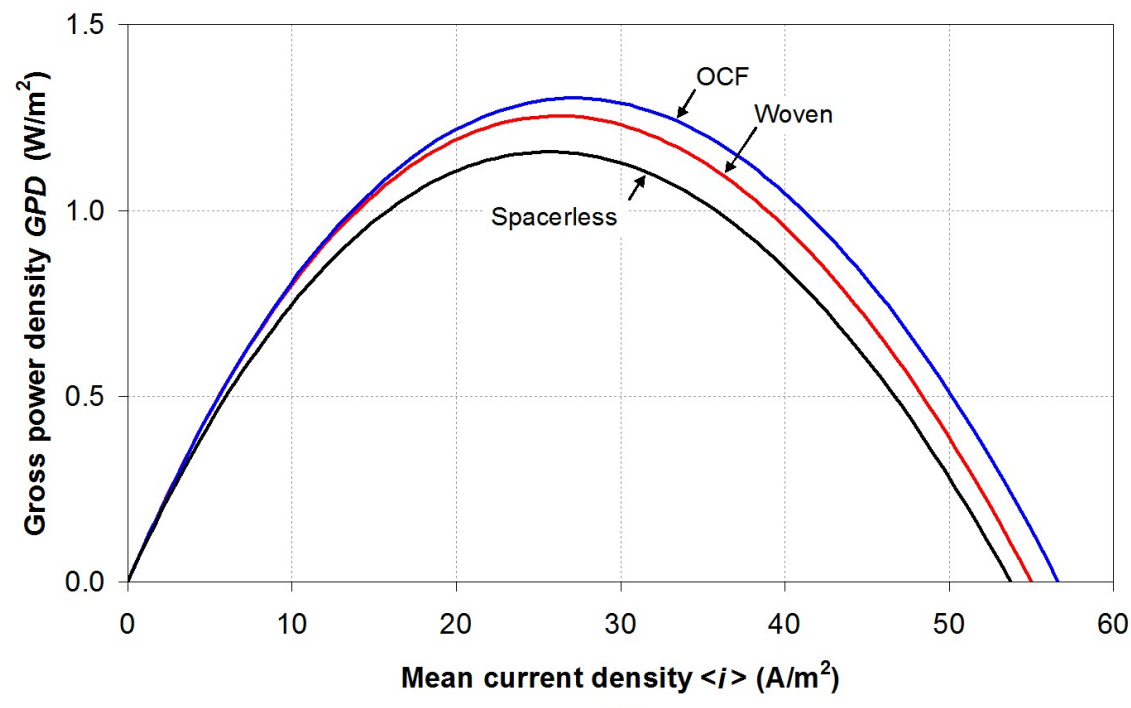

(a)

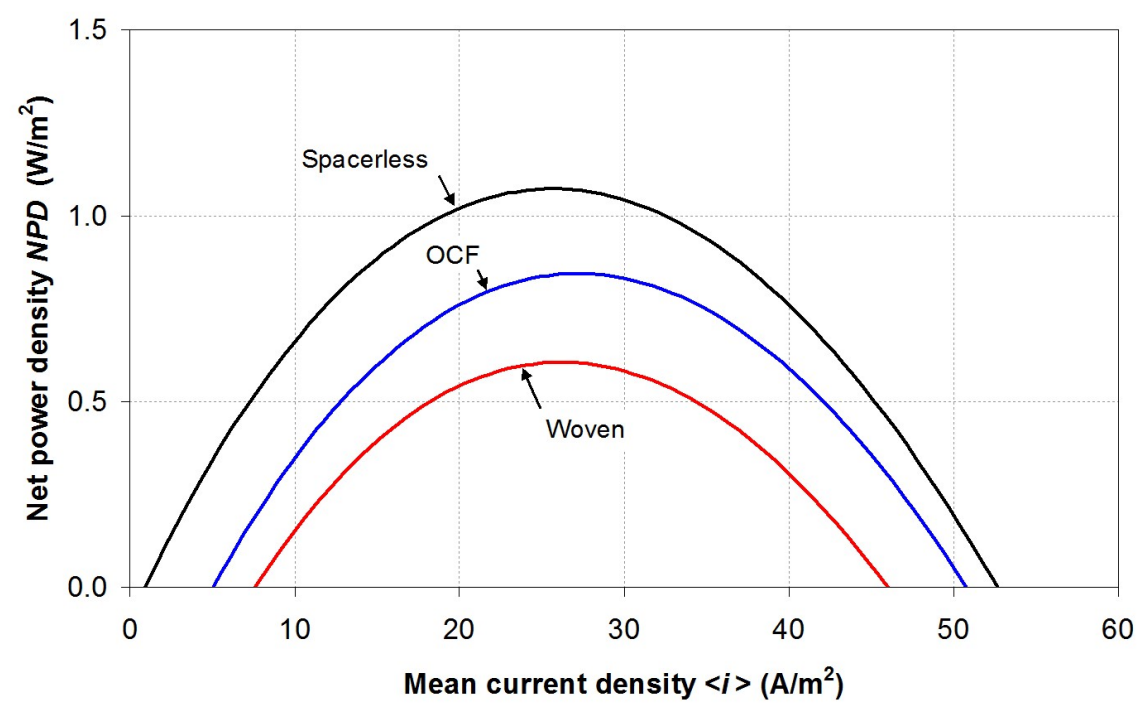

(b)

Figure 16. Summary results for the three geometries examined in the present study. (a) current densitygross power density curves; (b) current density-power density curves. See Table 1 for a description of the assumed conditions.

\section{MODEL VALIDATION}

As a caveat, it should be observed that validating a model for RED is not as neat a business as it would be validating, say, a CFD code. The reason is twofold: on one hand, any such model involves a large number of physico-chemical properties (e.g. membrane perm-selectivity, Ohmic resistance and osmotic / electro-osmotic permeability) which are known only approximately, and whose dependence on the solutions' concentrations is not fully characterized. On the other hand, measurements in real stacks are usually limited to global quantities such as the overall electromotive force and electric current, while data on local quantities such as electrical voltage, current density or concentration (which are typically predicted by a computational model) are rare. 
For a preliminary validation of the model we considered here two sets of data obtained with a different number of cell pairs in the stack and different membranes. In both cases the relevant quantity is the Gross Power Density measured as a function of the flow velocity in the channels.

The first set of data was presented by Veerman et al. [1], who used a stack with 50 cell pairs, $10 \times 10 \mathrm{~cm}$ in size, equipped with Fumasep FAD/FKD membranes, and the standard riverwater / seawater solutions $\left(C=500 / 17 \mathrm{~mol} / \mathrm{m}^{3}\right)$. The height of both the concentrate and the dilute channels was $200 \mu \mathrm{m}$ and the porosity of the woven spacer used was estimated to be $67 \%$. The membrane properties, as reported by the authors on the basis of their own measurements either in the same paper [1] or in a parallel study [34], are summarized in Table 2.

Table 2 - Membrane properties in seawater/riverwater as reported by Veerman et al. [1].

\begin{tabular}{|l|l|l|}
\hline Property & AEM & CEM \\
\hline Membrane type & Fumasep FAD (Fumatech) & Fumasep FKD (Fumatech) \\
\hline Thickness $H, \mu \mathrm{m}$ & 82 & 82 \\
\hline Permselectivity & 0.95 & 0.95 \\
\hline Ohmic areal resistance $R, \Omega \mathrm{m}^{2}$ & $1.63 \times 10^{-4}$ & $5.9 \times 10^{-4}$ \\
\hline Salt diffusivity $D_{S}, \mathrm{~m}^{2} / \mathrm{s}$ & $1.3 \times 10^{-11}[37]$ & $1.3 \times 10^{-11}[37]$ \\
\hline Water diffusivity $D_{W}, \mathrm{~m}^{2} / \mathrm{s}$ & $1.3 \times 10^{-9}[37]$ & $1.3 \times 10^{-9}[37]$ \\
\hline $\begin{array}{l}\text { Equivalent osmotic permeability } \\
L_{p}, \mathrm{ml} /\left(\mathrm{m}^{2} \mathrm{~h} \text { bar) }\right.\end{array}$ & $\sim 22$ & $\sim 22$ \\
\hline
\end{tabular}

Although the authors characterized osmotic fluxes through the membranes by reporting the water diffusivity, in order to facilitate comparisons we converted this into an osmotic permeability and expressed it in the usual units of $\mathrm{ml} /\left(\mathrm{m}^{2} \mathrm{~h}\right.$ bar $)$. In regard to quantities not explicitly reported by the authors, we assumed typical values, namely, $R_{\text {blank }}=10^{-2} \Omega \mathrm{m}^{2}$ for the areal resistance of the electrodes and $n_{H}=7$ for the hydration number (necessary to compute electro-osmotic fluxes).

Predictions obtained by the 1-D model are compared in Figure 17 with experimental results for different velocities of the solutions in the channels (Figure 6 of reference [1]). It can be observed that the model yields only a small overprediction of $G P D$ by $\sim 0.03 \mathrm{~W} / \mathrm{m}^{2}$, rather uniform in the velocity range considered. This small discrepancy is probably caused by non-ideal effects not considered in the model, such as parasitic currents or fouling. 


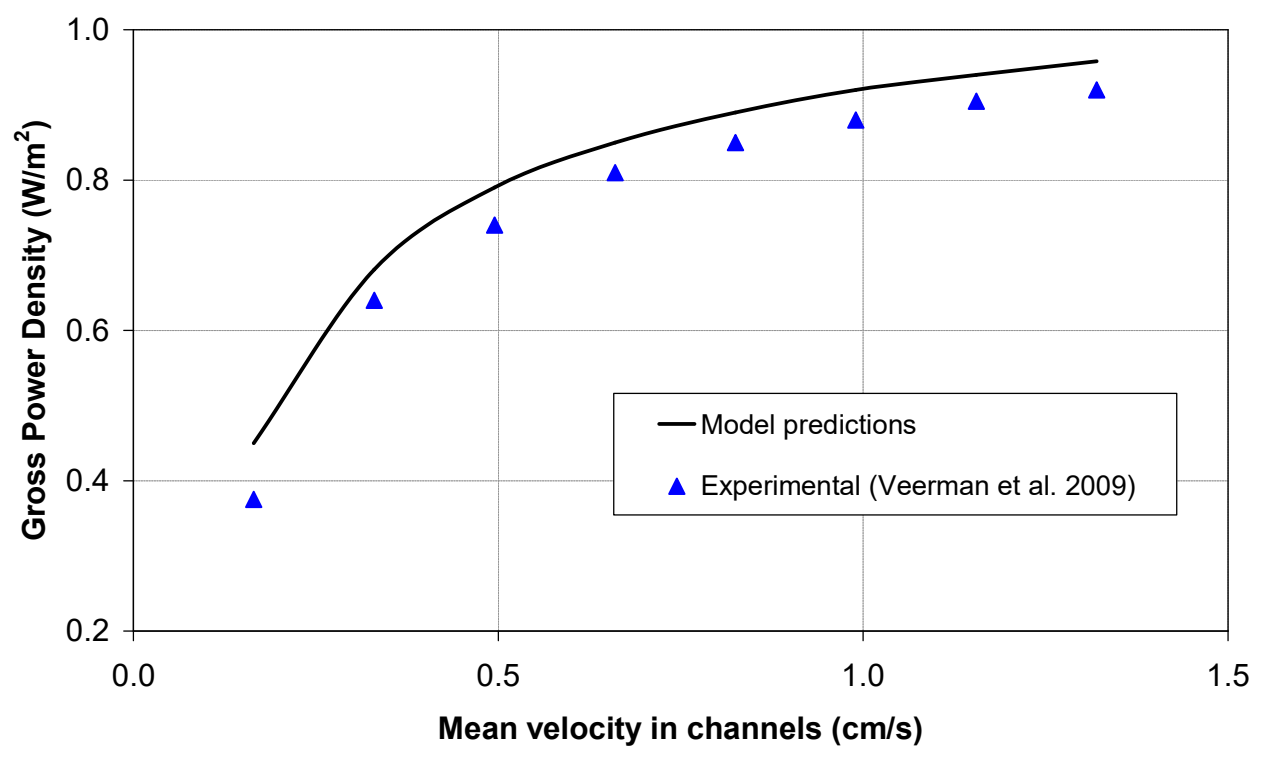

Figure 17. Comparison of the Gross Power Density $(G P D)$ predicted by the present model for different flow velocities with experimental results by Veerman et al. [1] (Fumasep membranes).

The second set of data was presented by Choi et al. [2], who used a small stack with only 1 cell pair, $5 \times 5 \mathrm{~cm}$ in size, equipped with Selemion AMV / CMV membranes and Ti-wire woven spacers. Membrane properties are reported in Table 3.

Table 3 - Membrane properties as reported by Choi et al. [2].

\begin{tabular}{|l|l|l|}
\hline Property & AEM & $C E M$ \\
\hline Membrane type & Selemion AMV & Selemion CMV \\
\hline Thickness $H, \mu \mathrm{m}$ & 120 & 120 \\
\hline Permselectivity & 0.94 & 0.94 \\
\hline Areal resistance $R, \Omega \mathrm{m}^{2}$ & $0.0033+0.031 / C^{D I L}$ & $0.0033+0.031 / C^{D I L}$ \\
\hline Salt diffusivity $D_{S}, \mathrm{~m}^{2} / \mathrm{s}$ & $3.1 \times 10^{-12}[37]$ & $3.1 \times 10^{-12}[37]$ \\
\hline Water diffusivity $D_{W}, \mathrm{~m}^{2} / \mathrm{s}$ & $1.2 \times 10^{-10}[37]$ & $1.2 \times 10^{-10}[37]$ \\
\hline $\begin{array}{l}\text { Equivalent osmotic permeability } \\
L_{p}, \mathrm{ml} /\left(\mathrm{m}^{2} \mathrm{~h} \text { bar }\right)\end{array}$ & $\sim 1.25$ & $\sim 1.47$ \\
\hline
\end{tabular}

Salt diffusivity and water diffusivity (this latter roughly corresponding to an osmotic permeability) are not reported in [2] but were measured for these membranes by Veerman et al. [37]. As in Galama et al. [36], the overall Ohmic resistance of the membranes was found to be a function of the dilute concentration only. Assuming this resistance to be equally distributed among AEM and CEM, the authors' measurements (Figure 3 in [2]), once expressed as an areal resistance per single membrane, can be approximated by the simple formula $r_{I E M}=0.0033+0.031 / C^{D I L}\left(r_{I E M}\right.$ in $\Omega \mathrm{m}^{2}, \mathrm{C}^{D I L}$ 
in $\mathrm{mol} / \mathrm{m}^{3}$ ), i.e. by a correlation of the same form as Eq. (23) but with different values of the constants $a, b$ and $c$. The salt hydration number was assumed to be $n_{H}=7$.

The height of concentrate and dilute channels was $200 \mu \mathrm{m}$ as in the previous example. The authors let the dilute concentration vary between $\sim 0.85$ and $\sim 34 \mathrm{~mol} / \mathrm{m}^{3}(0.05-2 \mathrm{~g} / \mathrm{l})$, while the concentrate was seawater $\left(C \approx 500 \mathrm{~mol} / \mathrm{m}^{3}\right)$ in all cases. They let also the velocity in the channels vary between $0.42 \times 10^{-2}$ and $2.5 \times 10^{-2} \mathrm{~m} / \mathrm{s}$ (flow rate $2.5-15 \mathrm{ml} / \mathrm{min}$ ). The gross power density, $G P D$, was estimated from voltage measurements taken between reference points internal to the electrodic compartments, so that it did not include the loss across the electrodes (which, in the case of a single cell pair, would be a considerable fraction of the electromotive force). The motion of the two solutions was in cross flow and followed the diagonals of the stack; however, for such short stack length $(5 \mathrm{~cm}$ side), the difference from the present model's assumption of parallel flow can be considered negligible.

Current density - gross power density curves, similar to those reported as examples in Figure 17(a), obtained by the 1-D model are compared with experimental results of [2] in Figure 18.

Figure $18(\mathrm{a})$ is for $U^{C O N C}=U^{D I L}=0.42 \mathrm{~cm} / \mathrm{s}$ (flow rate $2.5 \mathrm{ml} / \mathrm{min}$ ), $C^{C O N C}=500 \mathrm{~mol} / \mathrm{m}^{3}$ (seawater) and varying $C^{D I L}$, from $1.7 \mathrm{~mol} / \mathrm{m}^{3}$ to $34 \mathrm{~mol} / \mathrm{m}^{3}$. Maximum GPD values are predicted with fair accuracy; they first increase as $C^{D I L}$ decreases from 34 to $8.5 \mathrm{~mol} / \mathrm{m}^{3}$, due to the increased $C$-ratio in the Nernst expression of $O C V$, Eq. (11); however, a further reduction of $C^{D I L}$ causes $G P D$ to decrease since the increase in the Ohmic resistance of the dilute channels overwhelms the Nernst effect. This non-monotonic trend is well reproduced by the model, although $G P D$ is overestimated at the smallest dilute concentration $\left(1.7 \mathrm{~mol} / \mathrm{m}^{3}\right)$. Short circuit currents are overestimated at all concentrations, and particularly at low $C^{D I L}$, probably because parasitic current loops are present in the experiments but are not taken into account by the model.

Figure $18(\mathrm{~b})$ is for $C^{C O N C}=500 \mathrm{~mol} / \mathrm{m}^{3}, C^{D I L}=17 \mathrm{~mol} / \mathrm{m}^{3}$ and different values of the mean velocity $U$ in both channels, from 0.42 to $2.5 \mathrm{~cm} / \mathrm{s}$. It can be observed that $G P D$ increases with $U$, mainly because higher flow rates cause smaller axial voltage drops $\eta_{\Delta C}$ (associated with the axial decrease of the concentration ratio); beyond a certain value of $U$, further increments fail to cause significant increases of GPD because axial effects become negligible with respect to other sources of voltage drop (Ohmic and non-Ohmic losses). This behaviour is correctly reproduced by the model, although it somewhat underestimates the influence of the flow rate. 


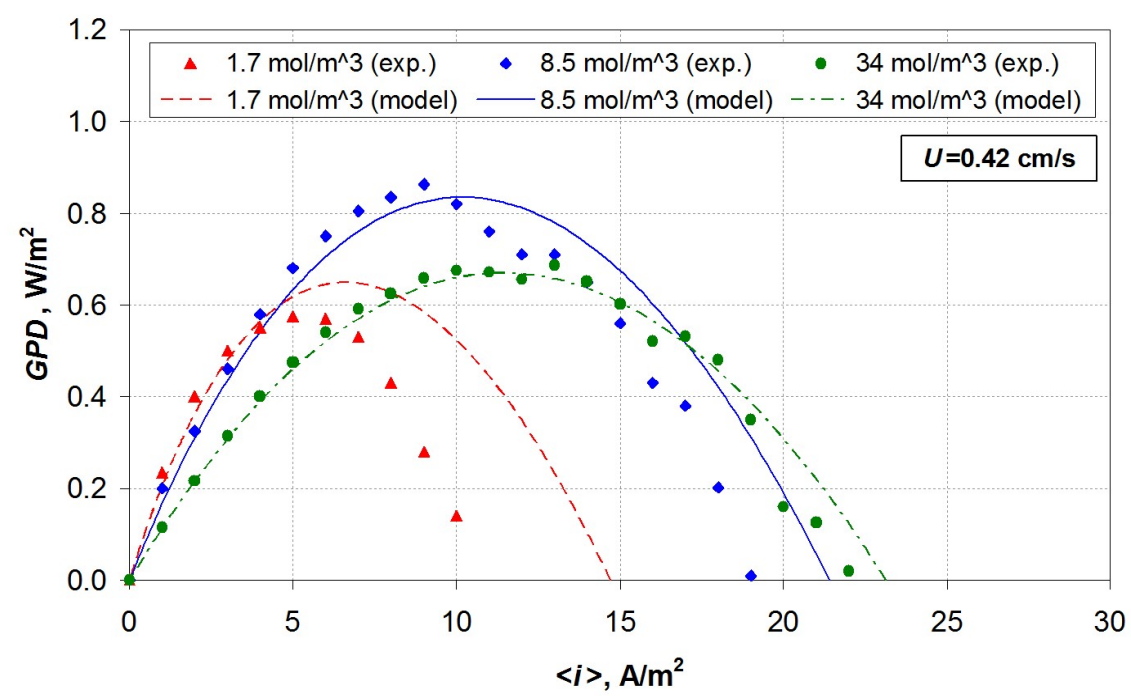

(a)

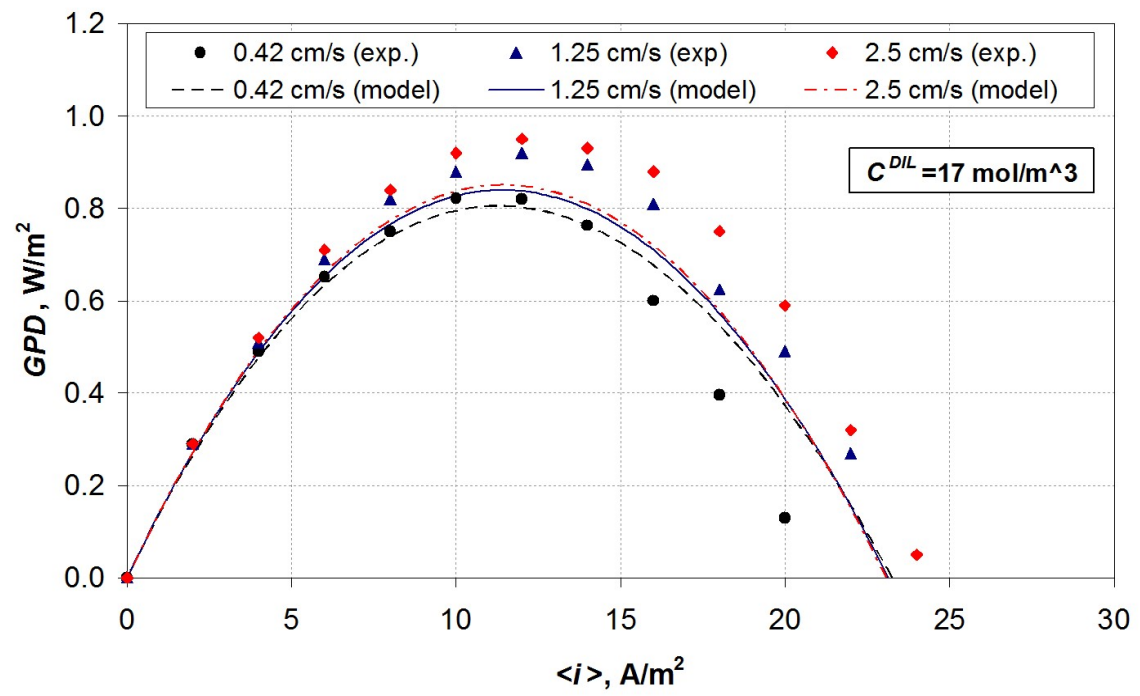

(b)

Figure 18. Comparison of the Gross Power Density $(G P D)$ predicted by the present model with experimental results by Choi et al. [2] (Selemion membranes). (a) $U^{C O N C}=U^{D I L}=0.42 \times 10^{-2} \mathrm{~m} / \mathrm{s}$, $C^{C O N C}=500 \mathrm{~mol} / \mathrm{m}^{3}$ and varying $C^{D I L}$; (b) $C^{C O N C}=500 \mathrm{~mol} / \mathrm{m}^{3}, C^{D I L}=17 \mathrm{~mol} / \mathrm{m}^{3}$ and varying velocity in the channels.

\section{CONCLUSIONS}

In this paper, we presented a coupled strategy for the prediction of RED stack performance, based on combining a one-dimensional model of the stack with fully three-dimensional finite volume simulations of the electrolyte channels, including complex configurations (spacers or profiled membranes). An advanced CFD code was used to provide Sherwood numbers and friction coefficients, related, in their turn, to polarization voltage losses and pumping power losses, respectively. Finite-volume 3-D computations were also used to provide areal Ohmic resistances.

Results were compared with literature data obtained in laboratory-scale stacks and a satisfactory overall agreement was observed. Under the conditions considered for these 
comparisons (short stacks, low current densities and thin channels provided with spacers) the terms computed by finite-volume simulations (Sherwood numbers, friction coefficients) were found to play a relatively secondary role. However, the passage to long stacks of industrial interest (e.g. 1 $\mathrm{m})$ will make an accurate estimate of friction coefficients crucial for the assessment of the net power density. Similarly, polarization losses in RED may become more important in the future, as membranes offering lower Ohmic resistances are developed; they may also be more important in ElectroDialysis, usually characterized by higher current densities, larger flow rates, and larger channel heights. Finally, the possible choice of thicker channels will make an accurate evaluation of boundary layer losses similarly important; and the adoption of profiled membranes in lieu of spacers will raise the problem of predicting the overall Ohmic resistance of the cell pair in complex spatial configurations.

In this perspective, the combined approach described in this paper constitutes a fully predictive, potentially very accurate, and still extremely fast-running, tool to investigate the potentials of alternative designs, to orient experimental activities and to design/optimize real RED equipment.

\section{Acknowledgements}

This work was funded within the Horizon 2020 programme by project RED Heat-to-Power (contract number 640667).

\section{NOMENCLATURE}

$\begin{array}{lll}\text { Symbol } & \text { Quantity } & \text { Unit } \\ \text { as; } a_{s, i} & \text { Driving acceleration } & \mathrm{m} \mathrm{s}^{-2} \\ C & \text { Bulk concentration } & \mathrm{mol} \mathrm{m}^{-3} \\ c & \text { Local concentration } & \mathrm{mol} \mathrm{m}^{-3} \\ c_{e x t} & \text { External concentration } & \mathrm{mol} \mathrm{m}^{-3} \\ D & \text { Salt diffusivity } & \mathrm{m}^{2} \mathrm{~s}^{-1} \\ d_{e q} & \text { Hydraulic diameter }(=2 \mathrm{H}) & \mathrm{m} \\ E & \text { Electromotive force per cell pair } & \mathrm{V} \\ F & \text { Faraday's constant, } 9.6485 \times 10^{4} & \mathrm{C} \mathrm{mol}^{-1} \\ f & \text { Darcy friction coefficient } & - \\ G & \text { Mass flow rate } & \mathrm{kg} \mathrm{s}^{-1} \\ G P D & \text { Gross Power Density per cell pair } & \mathrm{W} \mathrm{m}^{-2}\end{array}$




\begin{tabular}{|c|c|c|}
\hline $\mathrm{Gz}$ & Graetz number, $\mathrm{Pe} /\left(y / d_{e q}\right)$ & - \\
\hline$H$ & Thickness & $\mathrm{m}$ \\
\hline$I$ & Electrical current & A \\
\hline$i$ & Electrical current density & $\mathrm{A} \mathrm{m}^{-2}$ \\
\hline$J$ & Trans-membrane water flux & $\mathrm{m} \mathrm{s}^{-1}$ \\
\hline K & Singular pressure loss coefficient & - \\
\hline$k$ & Mass transfer coefficient, $N /\left(C-c_{\text {wall }}\right)$ & $\mathrm{m} \mathrm{s}^{-1}$ \\
\hline$L$ & Stack length & $\mathrm{m}$ \\
\hline$L_{p}$ & Osmotic permeability & $\mathrm{M} \mathrm{s}^{-1} \mathrm{~Pa}^{-1}$ \\
\hline$M$ & Molar mass & $\mathrm{Kg} \mathrm{mol}^{-1}$ \\
\hline$N$ & Molar flux & $\mathrm{mol} \mathrm{m}^{-2} \mathrm{~s}^{-1}$ \\
\hline$n_{C P}$ & Number of cell pairs in the stack & - \\
\hline$n_{H}$ & Hydration number & - \\
\hline$N P D$ & Net Power Density per cell pair & $\mathrm{W} \mathrm{m}^{-2}$ \\
\hline$O C V$ & Open circuit voltage per cell pair & $\mathrm{V}$ \\
\hline$P$ & Pitch of spacers or profiled membrane & $\mathrm{m}$ \\
\hline$p$ & Pressure & $\mathrm{Pa}$ \\
\hline$P P D$ & Pumping Power Density per cell pair & $\mathrm{W} \mathrm{m}^{-2}$ \\
\hline $\mathrm{Pe}$ & Peclet number, Re·Sc & - \\
\hline$Q$ & Volume flow rate & $\mathrm{m}^{3} \mathrm{~s}^{-1}$ \\
\hline$r$ & Areal electrical resistance per cell pair & $\Omega \mathrm{m}^{2}$ \\
\hline$R$ & Gas constant, 8.3415 & $\mathrm{~J} \mathrm{~mol}^{-1} \mathrm{~K}^{-1}$ \\
\hline$R_{\text {ext }}$ & External electrical resistance (load) & $\Omega$ \\
\hline $\operatorname{Re}$ & Void channel Reynolds number, $U d_{e q} / v$ & - \\
\hline$S$ & Projected surface area of stack, $L W$ & $\mathrm{~m}^{2}$ \\
\hline$S_{C}$ & Compensative source term & $\mathrm{mol} \mathrm{m} \mathrm{s}^{-3}$ \\
\hline $\mathrm{Sc}$ & Schmidt number, $v / D$ & - \\
\hline $\mathrm{Sh}$ & Sherwood number, $k \cdot d_{e q} / D$ & - \\
\hline$T$ & Absolute temperature & $\mathrm{K}$ \\
\hline$U$ & Void channel velocity, $Q /(H W)$ & $\mathrm{m} \mathrm{s}^{-1}$ \\
\hline$u_{j}$ & Generic velocity component & $\mathrm{m} \mathrm{s}^{-1}$ \\
\hline$V$ & Volume & $\mathrm{m}^{3}$ \\
\hline$V_{L O A D}$ & Voltage drop across the external load & $\mathrm{V}$ \\
\hline$v_{L O A D}$ & Ratio $V_{L O A D} / n_{C P}$ & $\mathrm{~V}$ \\
\hline
\end{tabular}


Stack width (spanwise extent) m

Generic coordinate m

$y$

Co-ordinate along the flow direction

$\mathrm{m}$

Dimensionless distance from inlet, $\left(y / D_{h}\right) / \mathrm{Pe} \quad$ -

\section{Greek symbols}

$\alpha$

$\gamma$

$\Delta p$

$\varepsilon$

$\eta$

$\vartheta$

$\mu$

$v$

$\pi$

$\rho$

$\sigma$

$\Phi$

$\varphi$

$\chi$

\section{Subscripts/superscripts}

AEM

$B L$

blank

CEM

CONC

COUL

CP

$D I F$

DIL

dist

E.OSM
Membrane permselectivity

Activity coefficient

Pressure drop $\quad \mathrm{Pa}$

Porosity, or void ratio, $\mathrm{V}^{\mathrm{SOL} / \mathrm{V}}$

Electrical voltage drop per cell pair $\quad \mathrm{V}$

Polarization coefficient, $\min \left(c_{\text {wall }} / C, C / c_{\text {wall }}\right) \quad-$

Viscosity

Pa s

Kinematic viscosity

$\mathrm{m}^{2} \mathrm{~s}^{-1}$

Osmotic pressure

$\mathrm{Pa}$

Density

$\mathrm{kg} \mathrm{m}^{-3}$

Electrical conductivity

$\mathrm{S} \mathrm{m}^{-1}$

Electrical potential

$\mathrm{V}$

Flow attack angle

$\operatorname{deg}$

Pump efficiency

Anion Exchange Membrane

Related to concentration boundary layer

Pertaining to electrodic compartments

Cation Exchange Membrane

Concentrated solution

Coulombic (proportional to $i$ )

Cell pair

Diffusive

Dilute solution

Distributed

Electro-osmotic 


$\begin{array}{ll}I E M & \text { Ion exchange membrane }(A E M / C E M) \\ k & \text { Inlet } \\ \text { LOAD } & \text { Generic material in a section of a cell pair } \\ \text { OSM } & \text { Electrical external load } \\ \text { OCV } & \text { Osmotic } \\ P & \text { Open circuit voltage } \\ r e f & \text { Working point } \\ S & \text { Reference concentration } \\ S C & \text { Salt } \\ S O L & \text { Short circuit } \\ \text { sing } & \text { Generic solution (CONC/DIL) } \\ W & \text { Singular pressure loss } \\ \text { wall } & \text { Water } \\ \Delta C & \text { Wall (solution-membrane interface) } \\ \Omega & \text { Related to axial changes in concentration } \\ & \text { Related to Ohmic effects }\end{array}$

Averages

Over the whole stack projected surface $S$

\{\}

Over one wall of one unit cell

\section{REFERENCES}

[1] J. Veerman, M. Saakes, S. J. Metz, G. J. Harmsen, Reverse electrodialysis: Performance of a stack with 50 cells on the mixing of sea and river water, J. Membr. Sci. 327 (2009) 136-144.

[2] Choi, I., Han, J. Y., Yoo, S. J., Henkensmeier, D., Kim, J. Y., Lee, S. Y., Han, J., Nam, S. W., Kim, H.-J., Jang, J. H., Experimental Investigation of Operating Parameters in Power Generation by Lab-Scale Reverse Electro-Dialysis (RED), Bull. Korean Chem. Soc. 37 (2016) 1010-1019.

[3] M. Tedesco, A. Cipollina, A. Tamburini, G. Micale, Towards $1 \mathrm{~kW}$ power production in a reverse electrodialysis pilot plant with saline waters and concentrated brines, J. Membr. Sci. 522 (2017) 226-236. 
[4] D. A. Vermaas, M. Saakes, K. Nijmeijer, Power generation using profiled membranes in reverse electrodialysis, J. Membr. Sci. 385-386 (2011) 234-242.

[5] D. A. Vermaas, J. Veerman, N. Y. Yip, M. Elimelech, M. Saakes, K. Nijmeijer, High Efficiency in Energy Generation from Salinity Gradients with Reverse Electrodialysis, ACS Sust. Chem. Eng. 1 (2013) 1295-1302.

[6] H. Strathmann, Ion-exchange membrane separation processes, first ed., Elsevier, Amsterdam, 2004.

[7] O. Scialdone, C. Guarisco, S. Grispo, A. D’Angelo, A. Galia, Investigation of electrode material - Redox couple systems for reverse electrodialysis processes. Part I: Iron redox couples, $J$. Electroanal. Chem. 681 (2012) 66-75.

[8] D. A. Vermaas, E. Guler, M. Saakes, K. Nijmeijer, Theoretical power density from salinity gradients using reverse electrodialysis, Energy Procedia 20 (2012) 170-184.

[9] A. Daniilidis, D. A. Vermaas, R. Herber, K. Nijmeijer, Experimentally obtainable energy from mixing river water, seawater or brines with reverse electrodialysis, Renew. Energy 64 (2014) $123-131$.

[10] J. W. Post, H. V. M. Hamelers, C. J. N. Buisman, Energy recovery from controlled mixing salt and fresh water with a reverse electrodialysis system, Environ. Sci. Technol. 42 (2008) 57855790 .

[11] P. Długołęcki, A. Gambier, K. Nijmeijer, M. Wessling, Practical potential of reverse electrodialysis as process for sustainable energy generation, Environ. Sci. Technol. 43 (2009) 6888-6894.

[12] S. Pawlowski, P. Sistat, J. G. Crespo, S. Velizarov, Mass Transfer in Reverse Electrodialysis: Flow Entrance Effects and Diffusion Boundary Layer Thickness, J. Membr. Sci. 471 (2014) 72-83.

[13] D. A. Vermaas, M. Saakes, K. Nijmeijer, Enhanced mixing in the diffusive boundary layer for energy generation in reverse electrodialysis, J. Membr. Sci. 453 (2014) 312-319.

[14] A. Tamburini, M. Tedesco, A. Cipollina, G. Micale, M. Ciofalo, M. Papapetrou, W. Van Baak, A. Piacentino, Reverse Electrodialysis heat engine for sustainable power production, submitted to Applied Energy, 2017.

[15] M. Tedesco, A. Cipollina, A. Tamburini, I. D. L. Bogle, G. Micale, A simulation tool for analysis and design of reverse electrodialysis using concentrated brines, Chem. Eng. Res. Des. 93 (2015) 441-456. 
[16] J. Veerman, M. Saakes, S. J. Metz, G. J. Harmsen, Reverse electrodialysis: A validated process model for design and optimization, Chem. Eng. J. 166 (2011) 256-268.

[17] D. A. Vermaas, M. Saakes, K. Nijmeijer, Doubled power density from salinity gradients at reduced intermembrane distance, Environ. Sci. Technol. 45 (2011) 7089-7095.

[18] P. Długołecki, P. Ogonowski, S. J. Metz, M. Saakes, K. Nijmeijer, M. Wessling, On the resistances of membrane, diffusion boundary layer and double layer in ion exchange membrane transport, J. Membr. Sci. 349 (2010) 369-379.

[19] L. Gurreri, A. Tamburini, A. Cipollina, G. Micale, M. Ciofalo, CFD prediction of concentration polarization phenomena in spacer-filled channels for reverse electrodialysis, $J$. Membr. Sci. 468 (2014) 133-148.

[20] J. Veerman, M. Saakes, S. J. Metz, G. J. Harmsen, Electrical power from sea and river water by reverse electrodialysis: A first step from the laboratory to a real power plant, Environ. Sci. Technol. 44 (2010) 9207-9212.

[21] S. Pawlowski, J. G. Crespo, S. Velizarov, Pressure drop in reverse electrodialysis: Experimental and modelling studies for stacks with variable number of cell pairs, J. Membr. Sci. 462 (2014) 96-111.

[22] J. Veerman, J. W. Post, M. Saakes, S. J. Metz, G. J. Harmsen, Reducing power losses caused by ionic shortcut currents in reverse electrodialysis stacks by a validated model, J. Membr. Sci. 310 (2008) 418-430.

[23] D.A. Vermaas, D. Kunteng, M. Saakes, K. Nijmeijer, Fouling in reverse electrodialysis under natural conditions, Water Res. 47 (2013) 1289-1298.

[24] Y. Tanaka, Pressure distribution, hydrodynamics, mass transport and solution leakage in an ion-exchange membrane electrodialyzer, J. Membr. Sci. 234 (2004) 23-39.

[25] Comsol, Inc., COMSOL Multiphysics Modeling Software, 2015.

[26] L. Gurreri, M. Ciofalo, A. Cipollina, A. Tamburini, W. Van Baak, G. Micale, CFD modelling of profiled-membrane channels for reverse electrodialysis, Desalin. Water Treat. 55 (2015) 3404-3423.

[27] A. Tamburini, G. La Barbera, A. Cipollina, G. Micale, M. Ciofalo, CFD prediction of scalar transport in thin channels for reverse electrodialysis, Desalin. Water Treat. 55 (2015) 3424-3445. 
[28] L. Gurreri, A.Tamburini, A.Cipollina, G.Micale, M.Ciofalo, Flow and mass transfer in spacer-filled channels for reverse electrodialysis: a CFD parametrical study, J. Membr. Sci. 497 (2016) 300-317.

[29] S. Pawlowski, V. Geraldes, J. G. Crespo, S. Velizarov, Computational fluid dynamics (CFD) assisted analysis of profiled membranes performance in reverse electrodialysis, J. Membr. Sci. $\mathbf{5 0 2}$ (2016) 179-190.

[30] M. Tedesco, H. V. M. Hamelers, P. M. Biesheuvel, Nernst-Planck transport theory for (reverse) electrodialysis: I. Effect of co-ion transport through the membranes, J. Membr. Sci. 510 (2016) 370-381.

[31] M. Tedesco, H. V. M. Hamelers, P. M. Biesheuvel, Nernst-Planck transport theory for (reverse) electrodialysis: II. Effect of water transport through ion-exchange membranes, J. Membr. Sci. 531 (2017) 172-182.

[32] A. A. Moya, Numerical simulation of ionic transport processes through bilayer ion-exchange membranes in reverse electrodialysis stacks, J. Membr. Sci. 524 (2017) 400-408.

[33] K. S. Pitzer, Thermodynamics of electrolytes: I. Theoretical basis and general, J. Phys. Chem. 77 (1973) 268-277.

[34] K. S. Pitzer, G. Mayorga, Thermodynamics of electrolytes. II. Activity and osmotic coefficients for strong electrolytes with one or both ions univalent, J. Physical Chem. 77 (1973) 2300-2308.

[35] L. Han, S. Galier, H. Roux-De Balmann, Ion hydration number and electroosmosis during electrodialysis of mixed salt solution, Desalination 373 (2015) 38-46.

[36] A. H. Galama, N. A. Hoog, D. R. Yntema, Method for determining ion exchange membrane resistance for electrodialysis systems, Desalination 380 (2016) 1-11

[37] J. Veerman, R. M. de Jong, M. Saakes, S. J. Metz, G. J. Harmsen, Reverse Electrodialysis: Comparison of six commercial membrane pairs on the thermodynamic efficiency and power density, J. Membr. Sci. 343 (2009) 7-15.

[38] F. Ponzio, A. Tamburini, A. Cipollina, G. Micale, M. Ciofalo, Experimental and computational investigation of heat transfer in channels filled by woven spacers, Int. J. Heat and Mass Transfer 104 (2017) 163-177.

[39] M. Ciofalo, M. Di Liberto, Fully developed laminar flow and heat transfer in serpentine pipes, International Journal of Thermal Sciences 96 (2015) 248-266. 
[40] M. La Cerva, M. Ciofalo, A. Tamburini, A. Cipollina, G. Micale, On some issues in the computational modelling of spacer-filled channels for membrane distillation, Desalination 411 (2017) 101-111.

[41] Ansys Inc., Ansys-CFX Reference Guide, Release 14.5, (2012).

[42] V. Gnielinski, VDI-Wärmeatlas, Springer-Verlag, Berlin, 1997.

[43] P.-S. Lee, S. V. Garimella, D. Liu, Investigation of heat transfer in rectangular microchannels, Int. J. Heat and Mass Transfer 48 (2005) 1688-1704.

[44] M. Shakaib, S. M. F. Hasani, M. Mahmood, CFD modeling for flow and mass transfer in spacer-obstructed membrane feed channels, J. Membr. Sci. 326 (2009) 270-284.

[45] W. Rohlfs, J. H. Lienhard, Entrance length effects on Graetz number scaling in laminar duct flows with periodic obstructions: Transport number correlations for spacer-filled membrane channel flows, Int. J. Heat and Mass Transfer 97 (2016) 842-852.

[46] D. W. Green, R. H. Perry, Perry's Chemical Engineers' Handbook, McGraw-Hill, New York, $8^{\text {th }}$ ed., 2007.

[47] H. Ozbek, J. A. Fair, S. L. Phillips, Viscosity of Aqueous Sodium Chloride Solutions from 0$150^{\circ} \mathrm{C}$, University of California, Berkeley, 1977.

[48] V. Vitagliano, P. A. Lyons, Diffusion coefficients for aqueous solutions of sodium chloride and barium chloride, J. Am. Chem. Soc. 76 (1956) 1549-1552.

[49] S. S. Islam, R. L. Gupta, K. Ismail, Extension of the Falkenhagen-Leist-Kelbg equation to the electrical conductance of concentrated aqueous electrolytes, J. Chem. Eng. Data 36 (1991) 102104. 
Annex 1: Correlations used for thermophysical and transport properties of $\mathrm{NaCl}$ solutions at $\mathrm{T}=25^{\circ} \mathrm{C}$ (concentration $C$ in $\mathrm{mol} / \mathrm{m}^{3}$ )

- Density $\rho\left(\mathrm{kg} / \mathrm{m}^{3}\right)$, best fit of data from Green and Perry [46]:

$\rho=5.94 \times 10^{-11} C^{3}-1.032 \times 10^{-6} C^{2}+4.097 \times 10^{-2} C+997$

- Viscosity $\mu(\mathrm{Pa} \cdot \mathrm{s})$, best fit of data from Ozbek et al. [47]:

$\mu=1.886 \times 10^{-15} C^{3}+5.260 \times 10^{-12} C^{2}+7.947 \times 10^{-8} C+0.8899 \times 10^{-3}$

- Kinematic viscosity $v\left(\mathrm{~m}^{2} / \mathrm{s}\right)$ :

$\nu=\mu / \rho$

- Salt diffusivity $D_{S}\left(\mathrm{~m}^{2} / \mathrm{s}\right)$, best fit of data from Vitagliano and Lyons [48]:

$D=1.47 \times 10^{-9}+0.13 \times 10^{-9} \cdot \exp (-C / 70)$

$(C \leq 400)$

$D=-2.87262 \times 10^{-21} \cdot C^{3}+2.03219 \times 10^{-17} \cdot C^{2}-8.44113 \times 10^{-15} \cdot C+1.4705 \times 10^{-9}$

- $\quad$ Activity coefficients $\gamma$ (dimensionless), bestfit of Pitzer's model [33, 34]:

$\gamma=0.64+0.189 e^{-C / 260}+0.1605 e^{-C / 20}$

$\gamma=0.64+0.189 e^{-C / 260}+0.1605 e^{-C / 20}+1.051 \times 10^{-7} \cdot(C-1200)^{1.8}$

- Osmotic pressure $\pi(\mathrm{Pa})$, bestfit of Pitzer's model $[33,34]$ :

$\pi=4.906 \times 10^{3} \cdot C^{0.9887}$

$(C \leq 1000)$

$\pi=1.359 \times 10^{3} \cdot C^{1.1745}$

$(C>1000)$

- Electrical conductivity $\sigma(\mathrm{S} / \mathrm{m})$, best fit of data from Islam et al. [49]:

$\log _{10}(\sigma)=-0.0027373 \cdot\left(\log _{10}(C)\right)^{3}-0.0059675 \cdot\left(\log _{10}(C)\right)^{2}+0.98994 \cdot\left(\log _{10}(C)\right)-1.9074$

$(C \leq 1000)$

$\log _{10}(\sigma)=-1.3893 \cdot\left(\log _{10}(C)\right)^{3}+13.252 \cdot\left(\log _{10}(C)\right)^{2}-41.277 \cdot\left(\log _{10}(C)\right)+43.011$

$(C>1000)$ 